NBER WORKING PAPER SERIES

\title{
MANDATED DISCLOSURE, STOCK RETURNS, AND THE 1964 SECURITIES ACTS AMENDMENTS
}

\author{
Michael Greenstone \\ Paul Oyer \\ Annette Vissing-Jorgensen \\ Working Paper 11478 \\ http://www.nber.org/papers/w11478
NATIONAL BUREAU OF ECONOMIC RESEARCH
1050 Massachusetts Avenue
Cambridge, MA 02138
June 2005

We are grateful to Lawrence Katz and two anonymous referees for insightful comments. We thank Joshua Angrist, Gary Becker, Howard Chang, Jeffrey Coles, Kent Daniel, Victor Lavy, Christian Leuz, Paul Mahoney, Derek Neal, Sam Peltzman, Christopher Polk, James Poterba, Roberta Romano, Sam SchulhoferWohl, Rene Stulz, and numerous seminar participants for suggestions. We thank Kenneth French for extending his factor series. Leila Agha, David Ahn, Neil Bhutta, James Caputo, Pauline Chen, Justin Gallagher, Yuan Hou, Jason Kilsdonk, Catherine Leblond, Yunling Lee, Adrian Mak, Zoe McManmon, Nora Richardson, Cheryl Sutherland, Sarah Tsee, Sarah Weber, Joe Winebrenner, Bill Young, Rosalind Young, and, especially, Scott Brave provided excellent research assistance. We are grateful to the Stigler Center at the University of Chicago, the John M. Olin Program in Law and Economics at Chicago and Stanford, Stanford University's Graduate School of Business, and Northwestern University's Kellogg School of Management for financial support. The views expressed herein are those of the author(s) and do not necessarily reflect the views of the National Bureau of Economic Research.

(O2005 by Michael Greenstone, Paul Oyer and Annete Vissing-Jorgensen. All rights reserved. Short sections of text, not to exceed two paragraphs, may be quoted without explicit permission provided that full credit, including $\odot$ notice, is given to the source. 
Mandated Disclosure, Stock Returns, and the 1964 Securities Acts Amendments

Michael Greenstone, Paul Oyer and Annette Vissing-Jorgensen

NBER Working Paper No. 11478

July 2005

JEL No. G28, G38, K22, L51, M41, M49, N22

\begin{abstract}
$\underline{\text { ABSTRACT }}$
The 1964 Securities Acts Amendments extended the mandatory disclosure requirements that had applied to listed firms since 1934 to large firms traded Over-the-Counter (OTC). We find several pieces of evidence indicating that investors valued these disclosure requirements, two of which are particularly striking. First, a firm-level event study reveals that OTC firms most impacted by the 1964 Amendments had abnormal excess returns of about 3.5 percent in the weeks immediately surrounding the announcement that they had begun to comply with the new requirements. Second, we estimate that the most affected OTC firms had abnormal excess returns ranging between 11.5 and 22.1 percent in the period between when the legislation was initially proposed and when it went into force, relative to unaffected listed firms and after adjustment for the standard four-factor model. While we cannot determine how much of shareholders' gains were a transfer from insiders of these same companies, our results suggest that mandatory disclosure causes managers to more narrowly focus on the maximization of shareholder value.

$\begin{array}{lll}\text { Michael Greenstone } & \text { Paul Oyer } & \text { Annette Vissing-Jorgensen } \\ \text { MIT Department of Economics } & \text { Graduate School of Business } & \text { Department of Finance } \\ \text { E52-391B } & \text { Stanford University } & \text { Kellogg School of Management } \\ \text { 50 Memorial Drive } & \text { 518 Memorial Way } & \text { Northwestern University } \\ \text { Cambridge, MA 02142-1347 } & \text { Stanford, CA 94305-5015 } & \text { 2001 Sheridan Road } \\ \text { and NBER } & \text { and NBER } & \text { Evanston, IL 60208-2001 } \\ \text { mgreenst@mit.edu } & \text { pauloyer@stanford.edu } & \text { and NBER } \\ & & \text { a-vissing@ northwestern.edu }\end{array}$
\end{abstract}




\section{INTRODUCTION}

Since the passage of the Securities Act of 1933 and the Securities Exchange Act of 1934, the federal government has actively regulated U.S. equity markets. The centerpiece of these efforts is the mandated disclosure of financial information. Proponents of securities market regulations cite cross-country studies that find that higher levels of investor protection, such as mandatory disclosure requirements, are associated with less concentrated ownership, larger equity markets, and higher valuations of equities (La Porta, Lopez-de-Silanes, and Shleifer [1999], La Porta, Lopez-de-Silanes, Shleifer, and Vishny [1997, 2002]). Although cross-country studies are likely to confound numerous effects, these empirical findings suggest that mandatory disclosure laws may provide access to equity on more favorable terms for entrepreneurs. Furthermore, given the link between financial development and growth (Rajan and Zingales [1998] and Castro, Clementi, and MacDonald [2004]), these laws may lead to higher standards of living.

Previous research that is narrowly focused on mandatory disclosure laws, however, provides mixed evidence on their impacts. Theoretical models suggest that these laws can be beneficial when the costs of writing or enforcing contracts that bind managers to maximize shareholder value are sufficiently high. Although the first empirical evaluations of mandatory disclosure laws were published four decades ago (Stigler [1964], Friend and Herman [1964], Robbins and Werner [1964], and Benston [1973]), the extensive subsequent literature has failed to reach a consensus (Coffee [1984], Healy and Palepu [2001]). The absence of convincing evidence has led some legal scholars to recommend significant modification or repeal of the statutes that regulate U.S. securities mar-

kets, including the mandatory disclosure requirements (Mahoney [1997], Romano [1998], Palmiter [1999]).

This paper presents new evidence on the impacts of mandatory disclosure laws by analyzing the effect of the 1964 Securities Acts Amendments on stock returns and operating performance of firms newly affected by this legislation. The 1964 Amendments are the last major mandatory disclosure regulations applied to U.S. equity markets. They extended the disclosure requirements that have applied to firms traded on exchanges (e.g., the New York and American Stock Exchanges, henceforth NYSE and AMEX) since 1934 to firms traded Over-the-Counter (OTC) that exceeded asset and shareholder floors. Specifically, covered OTC firms were required to: (1) register with the SEC; (2) provide regular updates on their financial position, such as audited balance sheets and income statements; (3) issue detailed proxy statements to shareholders, and (4) report on insider holdings and trades.

The 1964 Amendments provide a compelling setting for evaluating the consequences of manda- 
tory disclosure regulations for at last two reasons. First, this legislation did not affect all firms equally. One category of OTC firms was entirely free of all mandatory disclosure requirements before 1964, but were required to comply with all four types of disclosure after the law. The 1964 legislation required a second set of OTC firms, which was already fulfilling (1) and (2), to begin complying with (3) and (4). Small OTC firms below the asset or shareholder floors were only affected by the 1964 Amendments if they grew above the size cutoffs. In contrast, NYSE and AMEX firms were entirely unaffected by the law, because they had been subject to all four of the mandatory disclosure requirements since the 1934 legislation.

We compare the stock returns and changes in operating performance of affected OTC firms with NYSE/AMEX firms. We also contrast these outcomes among OTC firms that are differentially affected by the 1964 Amendments. This research design provides an opportunity to avoid confounding the effect of the law with unobserved shocks to all firms' stock returns and operating performance. This feature of the analysis is an improvement on much of the previous empirical research on mandatory disclosure laws (e.g., Stigler [1964], Friend and Herman [1964], Robbins and Werner [1964], Jarrell [1981]). ${ }^{1}$

Second, the timing of the debate, passage, and initial enforcement of the Amendments generates potentially informative inter-temporal variation in the expected effects of the law. During the period from January 1, 1963 through November 15, 1965, which we label Period 1, the 1964 Amendments were initially proposed and passed into legislation, and it was revealed which individual firms registered with the SEC. If market participants expected the disclosure requirements to produce information that they valued, we expect positive abnormal excess returns for affected OTC firms (relative to unaffected NYSE/AMEX firms) in this period.

During the period which runs from November 15, 1965 through the end of 1966, labeled Period 2 , virtually no new information about the law or which firms would comply with its requirements was revealed. This period is therefore used to assess the validity of our approach. Specifically, failure to reject the null of zero abnormal excess returns for affected OTC groups in this period

\footnotetext{
${ }^{1}$ Chow [1983], Simon [1989], and Bushee and Leuz [2005] are important exceptions in that they exploit variation in how mandatory disclosure laws affected different categories of firms. Chow [1983] found that the 1933 Act lowered shareholder value, though the generality of his findings are limited by the paper's small sample size. Simon [1989] found that investor forecast errors (the dispersion of abnormal returns) were lower following the 1933 Securities Act. Her sample is limited to newly issued securities. Bushee and Leuz [2005] examine the imposition of the same set of disclosure requirements as those in the 1964 Amendments, when these were applied to the small companies traded on the OTC Bulletin Board in 1999. They find that a large fraction of firms delist in response to the increased disclosure requirements and the decision to delist is associated with a 6 to 25 percent decline in market capitalization. Companies in their sample had a mean market capitalization of roughly $\$ 9$ million $(2005 \$)$, while the firms in our sample that were newly required to begin complying with all four forms of mandatory disclosure under the 1964 legislation had a mean (median) market capitalization of approximately $\$ 280$ million (\$57 million) (2005\$).
} 
provides support for the validity of our research design and any findings from Period 1.

One reason that the 1964 Amendments have not been studied widely is that electronic data on OTC firms is unavailable in this period. We created the equivalent of the Center for Research in Security Prices (CRSP) data set for a large sample of OTC firms from 1963 through 1966. We combined OTC stock price listings in printed versions of Barron's newspapers and data from eleven other publications to create a data file with information on share prices, dividends, stock splits, mergers, name changes, liquidations, accounting variables, and the SEC filing status of 1,196 OTC firms. The resulting file is combined with data on NYSE/AMEX firms from the CRSP and COMPUSTAT data files, supplemented with accounting data collected for NYSE/AMEX firms not covered in COMPUSTAT.

The analysis begins with the most direct test available to us of whether shareholders valued the disclosure requirements. A firm-level event study reveals that complying OTC firms had abnormal excess returns of about 3.5 percent in the weeks immediately surrounding the announcement that they had begun to comply with the new requirements. An appealing feature of this test is that the date of these announcements varied from firm to firm.

Additional evidence that investors valued the 1964 Amendments comes from comparisons of Period 1 returns across groups of OTC firms. We find that firms that were required to begin complying with all four disclosure requirements outperformed firms that were only required to begin complying with disclosure types (3) and (4). The most affected firms also outperformed OTC firms that were not targeted by the legislation. These differences in returns are generally statistically significant at conventional levels.

To evaluate the total effect of the 1964 Amendments, we turn to the full Period 1. In this period, estimates from a series of specifications indicate that OTC firms that were newly required to begin complying with all four forms of mandatory disclosure had statistically significant positive abnormal excess returns ranging between 11.5 and 22.1 percent, relative to size and book to market matched NYSE/AMEX firms. The estimates are derived from regression models that adjust for the market return and the size, book-to-market, and momentum factors (Fama and French [1993], Carhart [1997]). They imply that the 1964 Amendments created $\$ 3.2$ to $\$ 6.2$ Billion (2005\$'s) of value for shareholders of the OTC firms in our sample. Furthermore, in Period 2, we cannot reject the null hypothesis of zero abnormal excess returns for the OTC firms in any specifications, suggesting that these firms do not generally outperform the NYSE/AMEX firms.

We also test whether affected firms' operating performance improved after the Amendments were in force. We find that the most affected OTC firms had greater income and sales growth from 1962 to 1966 than unaffected NYSE/AMEX firms. This result suggest that the market's 
expectations of improved performance were justified and helps to explain these firms' higher stock returns.

Factor adjustments are critical for only one of our findings. In Period 1, the most affected OTC firms' stock returns exceed the returns of the unaffected NYSE/AMEX firms in the raw, unadjusted data, but this difference is not statistically different than zero. Factor adjustment does not drive the event study results, the most affected OTC firms' high returns relative to the other OTC firms in Period 1, the Period 2 results, or the operating performance results.

Overall, the results suggest that the benefits of the 1964 Amendments substantially outweighed the cost of complying with this law as measured by stock returns. This implies that the affected firms were not managed to maximize shareholder value prior to 1964 . We cannot determine whether this was because managers made negative net present value "empire building" acquisitions, lavished excessive salaries or perks on themselves, engaged in insider trading that reduced the liquidity of the firm's shares, or some other mechanism. Regardless of the exact channel, these findings are consistent with the notion that mandatory disclosure laws can cause managers to more narrowly focus on the maximization of shareholder value. This finding is a necessary condition for a positive welfare effect, but it is not sufficient, because we cannot rule out the possibility that managers lost an amount equal to that gained by shareholders. ${ }^{2}$

In the next section, we describe prior theoretical views on the value of mandatory disclosure and briefly review a model that helps frame our empirical analysis. In Section III, we provide some historical background on disclosure regulation in U.S. equity markets and explain in more detail why the 1964 Amendments provide a compelling environment to study the effects of mandatory disclosure laws. Sections IV and V describe our data and our empirical methodology, respectively. The empirical results are presented in Section VI and interpreted in Section VII. Section VIII concludes.

\section{Theoretical Perspectives on Disclosure Regulation}

Here, we briefly review the broad arguments in favor of and against mandatory disclosure requirements in securities markets. ${ }^{3}$ We also review the Shleifer and Wolfenzon [2002] model of

\footnotetext{
${ }^{2}$ To our knowledge, Ferrell [2004] is the only other empirical analysis of the 1964 Securities Acts Amendments. We discuss this paper and contrast it with ours in the interpretation section.

${ }^{3}$ See Verrecchia [2001] for a review of the theoretical financial disclosure literatures in accounting, economics, and finance and Easterbrook and Fischel [1984] for a discussion of legal scholarship's evidence on mandatory disclosure.
} 
financial markets when insiders can divert firm resources. This model provides a framework to interpret our empirical analysis.

\section{II.A. Theoretical Background}

One traditional view of securities market regulation, often attributed to Stigler [1964] and Coase [1960], is that government intervention is at best ineffective and, at worst, damaging. The basis of this view is that private contracts, combined with the possibility of litigation, between shareholders on the one side and managers, underwriters, auditors, and analysts on the other, is a cost effective way to achieve efficient disclosure. This private enforcement will be especially successful in settings with repeated interactions where agents with superior information are concerned about their reputations.

These views imply that a firm's failure to provide some information must be due to the high costs of provision, lack of value relevance, or valid concerns that competitors may benefit from its release. In this setting, mandatory disclosure regulations are either inconsequential or cause firms to release an inefficiently large amount of information.

An alternative view posits that prohibitively high costs of writing and enforcing complete contracts make mandatory disclosure regulations welfare enhancing. There are at least three reasons that regulations may be preferable to an exclusive reliance on private contracts. First, the costs of filing a lawsuit may introduce a free-rider problem among shareholders. In contrast, a regulator does not face these coordination problems. Second, regulations that mandate increased provision of information may be less vulnerable to subversion of justice than litigation (see Glaser and Shleifer [2003]). Third, regulators' exclusive focus on securities cases may make them more effective than judges or juries at detecting fraud.

\section{$\underline{\text { II.B. Conceptual Framework }}$}

The starting point of the Shleifer and Wolfenzon [2002] model of financial markets is that private contracts cannot set the expected penalties for diversion of firm profits by insiders high enough to deter all diversion. We define diversion as any activity that does not maximize shareholder value, including, but not limited to, expropriation of the cash flow for insiders' personal use, empire building (e.g., negative net present value investments that increase insiders' utility), and insider trading, which reduces liquidity and thus the value of equity.

Shleifer and Wolfenzon [2002] consider an entrepreneur who needs outside funding to bring her ideas to market. In exchange for these investments, she promises the outside shareholders a fraction 
of the future cash flow. The entrepreneur retains control of the firm, but she cannot credibly commit to zero diversion before paying out dividends.

The price that outside shareholders will pay for a given fraction of shares depends on their expectation of the degree of diversion, which depends on the magnitude of the contracting problem. Outsiders invest contingent upon an expected return at least as great as on alternative investments. In equilibrium, entrepreneurs divert firm resources and outside shareholders receive the market return on their investment. The key insight is that stock returns do not depend on the level of diversion, but stock prices do.

In this setting, consider the introduction of a regulatory policy that increases the expected penalties for diversion, either by increasing the probability of detection or raising the penalty. This policy will reduce the equilibrium level of diversion and, in turn, affect insiders' total payoff and firms' share prices. Consequently, such a policy will have distributional effects and may also impact welfare. These effects will differ for firms organized before and after the policy's introduction.

Consider firms that sold shares to the public before the policy was in force. The introduction of the policy unexpectedly increases the expected penalties for diversion. This lowers the equilibrium amount of diversion by entrepreneurs, which increases expected dividend payments to shareholders. This causes a one-time increase in the value of these firms. However, after this jump in the stock price, the return to holding shares in the firm will again equal the market return.

The increased stock price does not necessarily indicate an increase in welfare. Social welfare is unaffected when the abnormal returns are solely due to a transfer of a fixed set of resources from one party (the entrepreneur) to another (outside investors). However, when diversion is costly (e.g., if the total cost of a lavish office exceeds the entrepreneur's private valuation), the reduced diversion will generate welfare improvements.

Our paper tests whether the introduction of the 1964 Securities Acts Amendments led to abnormal stock returns for firms that existed before the legislation was seriously considered. A rejection of the null of zero abnormal stock returns for affected firms would suggest that the information revelation induced by the law was valued by outside shareholders. The basis for this test is the notion that the 1964 Amendments unexpectedly decreased the expected benefit of diversion for insiders by increasing the expected penalties. Although diversion is unobservable, we will also test whether affected firms' operating performance improved after the Amendments were in force.

Finally, in the context of the model, a finding of positive abnormal returns can be interpreted as a necessary but not sufficient condition that the 1964 Amendments increased welfare. Shleifer and Wolfenzon [2002] consider the case of firms that sell shares to the public after the regulatory policy is in place. They show that the higher expected penalties for diversion affect entrepreneurs' 
incentives so that in equilibrium there is less diversion and a more efficient allocation of resources across entrepreneurs. This theoretical finding highlights that the potential welfare gains from mandatory disclosure laws extend beyond any gains associated with the set of firms that were established before such laws were in force. However, an empirical examination of this prediction is beyond the scope of the current paper.

\section{Background on Federal Disclosure Regulations and a New Research Design}

Our empirical analysis examines the impact of the 1964 Securities Acts Amendments on the stock returns and operating performance of affected firms. This section provides a brief history of securities laws before the 1964 Amendments and how the structure of the legislation and the timing of its passage and implementation provide a compelling research design to test for the effects of mandatory disclosure laws. ${ }^{4}$

$\underline{\text { III.A. Federal Regulation of Securities Markets Before } 1964}$

Prior to 1933, there was little federal regulation of securities markets. The 1933 Securities Act and the 1934 Securities Exchange Act marked a revolutionary foray into the regulation of securities markets by the federal government. The 1934 Act created four mandatory disclosure requirements that applied to some, but not all, existing firms. Here, we describe these disclosure requirements and detail which categories of firms were required to comply with each of them. Specifically, they are:

1. Firms listed on exchanges (such as the NYSE or AMEX) and OTC firms that had issued securities of sufficient market value after May 1936 were required to register these securities with the SEC. The registration statements had to contain detailed financial information at the time of registration, including: balance sheet and profit and loss statements from the previous three years; the terms and position of each class of outstanding securities; the organization, financial structure, and nature of the business; and the identity and remuneration of directors, officers, and shareholders with more than a ten percent stake.

2. Firms listed on exchanges (such as the NYSE or AMEX) and OTC firms that had issued securities of sufficient market value after May 1936 were required to file annual reports (Form

\footnotetext{
${ }^{4}$ This section draws heavily from Seligman [1995], as well as New York Times and Wall Street Journal articles from the 1960's. See these sources for more detailed legislative histories. See Mahoney [1995] for details on the pre-1930's history of disclosure regulation and Mahoney [2003] for a discussion of state "Blue Sky" laws.
} 
10-K) and semi-annual reports (Form 9-K) with the SEC. They were also required to report material events as they occurred (Form $8-\mathrm{K}) .{ }^{5}$

3. Firms listed on exchanges were required to provide proxy statements in advance of shareholder meetings or votes. These statements must contain information on the qualifications of directors and nominees for directors, executive compensation, and transactions between the company and its officers or directors. All OTC firms were exempted from this requirement.

4. Firms listed on exchanges were required to report the identities of officers, directors, and large shareholders. They also had to report these individuals' holdings of any equity security of the company and provide monthly statements of any changes. Companies could recover any profits that an insider realized from the purchase and sale of the company's stock in any period of less than six months. ${ }^{6}$ All OTC firms were exempted from this requirement.

Thus, the 1933 and 1934 Acts created a system of regulation that imposed different requirements on firms, based on where their shares were traded and whether they had made substantial public offerings after 1936.

To summarize, all listed firms were subject to all four disclosure requirements, OTC firms that had made substantial public offerings since 1936 were subject to requirements (1) and (2) above, and OTC firms that had not made a public offering since 1936 were free from all disclosure requirements no matter their size or how widely distributed their securities. Harvard Law Professor Louis Loss [1983] said this system of regulation created, “...a double standard of investor protection - a standard that resulted, more by accident than by design, from the piecemeal adoption of the SEC statutes but that nevertheless glowed with an incandescent illogic..." (pp. 462-463).

The available evidence suggests that the relatively lax disclosure requirements for OTC firms helped to create an environment where shareholders of these companies were often poorly informed and had few avenues available to penalize management for failing to maximize shareholder value. For example, in a study of a random sample of OTC securities conducted in 1962, the SEC found that: more than a quarter of the firms did not provide any reports on the firms' financial position or results in that year; 73 percent of proxy solicitations involving the election of directors failed to

\footnotetext{
${ }^{5}$ The requirement that OTC firms with new offerings comply with the periodic reporting requirements was added in separate legislation passed in 1936. This legislation exempted firms for which the total market capitalization for each security class issued was less than $\$ 2$ million after the offering. Further, a firm could cease filing these reports if and while the value of the security class of the newly issued security dropped below $\$ 1$ million.

${ }^{6}$ Under this law, it was legal to trade on private information if the shares were held for longer than six months. In 1968, a federal court gave the SEC the right to penalize all insider trading.
} 
include the names of the nominees; only 16 percent of these solicitations listed the directors' qualifications; 95 percent of proxy solicitations for election of directors failed to report on management compensation; 24 percent of the firms failed to solicit proxies before shareholder meetings; and in two-thirds of the solicitations involving modifications of securities, the effects of the modification on the rights of existing security holders were not given (United States Securities and Exchange Commission [1963]).

Even if OTC firms released independently audited financial statements, the information may not have been considered credible by market participants. In the case of firms not covered by the 1934 Securities Act, state courts had generally ruled that investors could not sue accountants for negligently prepared financial statements unless they had direct dealings with them (see Augenbraun's [1993] discussion of "privity"). In principle, investors in these companies could sue accountants for fraudulent statements, but, in practice, the legal standard for fraudulence was very difficult to meet. Consequently, these investors had little scope to penalize fraudulence through the courts. In light of these findings, it may not be surprising that Seligman [1995] contends that the "vast majority of securities fraud occurred among firms not subject to the SEC's period reporting requirements" (pp. 313-4).

Moreover, it was widely believed that many OTC firms chose not to list on exchanges precisely to avoid the stricter disclosure requirements on the NYSE and AMEX. ${ }^{7}$ Although we were unable to determine the precise listing requirements of the NYSE and AMEX in this period, market capitalization has always been an important factor in determining eligibility for listing on these exchanges. In our sample of 1196 OTC firms, there are 1,033 firms for which we could determine their market value at the start of 1963. 532 (206) of these firms had a market capitalization that exceeded the 25th (50th) percentile market capitalization of firms on the NYSE and AMEX measured at the same time. It is evident that numerous OTC firms that appeared eligible for trading on the more liquid NYSE/AMEX chose to remain on the OTC despite the apparent benefits to their shareholders from a switch.

$\underline{\text { III.B. Negotiation and Passage of the } 1964 \text { Amendments }}$

Between 1934 and 1961, it was not uncommon for SEC staffers, legislators, or other prominent public figures to call for an extension of the mandated reporting requirements to rectify the seemingly arbitrary inequities in regulatory intensity. However, these recommendations never seemed to gain any traction in Congress (see Loss [1983], page 464.) For example, Senator Frear of Delaware

\footnotetext{
${ }^{7}$ See United States Securities and Exchange Commission [1963] (especially, Part III, p. 16). Hereafter, we refer to this as the Special Study.
} 
introduced a bill to extend mandatory disclosure in 1949, but no action was taken because attention turned to higher priorities such as the Korean War (Special Study, part 3, page 7). In 1961, William Cary, the new head of the SEC, called for the extension of the disclosure requirements to OTC firms but his call failed to produce any real legislative action, like the previous calls for reform.

The political climate about extending mandatory disclosure requirements to OTC securities changed in the wake of the SEC's release of the first part of the Special Study in April, 1963. This study had been commissioned by Congress and the SEC's mandate was to examine the functioning of U.S. equity markets generally - not necessarily with a focus on OTC firms. But, based on the findings about the operation of OTC firms (some of which were discussed in the previous subsection), William Cary included a letter in the Special Study stating that the SEC would make several legislative recommendations, including expanding the disclosure requirements for OTC securities.

The Senate quickly reacted. On July 9, 1963, a subcommittee unanimously approved a bill extending disclosure rules to all OTC firms. On July 30, 1963, the full Senate passed the Securities Act Amendment which held OTC firms with at least $\$ 1$ million of assets and 500 shareholders to the same disclosure rules as the 1934 Act imposes on securities traded on the NYSE and AMEX.

The bill languished in the House for more than half a year until the winter of 1964 when President Johnson made two public endorsements of the legislation before the House. ${ }^{8}$ A House subcommittee passed the bill on March 19, 1964 and it was evident that it would soon become law. The full House and Senate passed identical versions of the bill on August 5 and 6, 1964 and Johnson signed it into law on August 20, 1964.

The law required that any OTC firm with at least 750 shareholders and $\$ 1$ million of assets as of the last day of its first fiscal year to end after July 1, 1964 (or any year after that) must register with the SEC within 120 days of the end of the fiscal year and begin to comply with the other three types of disclosure. ${ }^{9}$ Based on 1961 asset and shareholder data, the Special Study estimated that roughly 32 percent of OTC firms exceeded both the asset and shareholder floors. OTC firms with fewer than 500 shareholders and/or $\$ 1$ million in assets were unaffected by the 1964 Amendments.

III.C. The 1964 Amendments as a New Research Design

\footnotetext{
${ }^{8}$ The hold-up in the House was over the precise asset and shareholder floors and whether the insurance and banking industries should be exempted. The bill's general principle of increased disclosure was never seriously contested. The U.S. Chamber of Commerce and National Association of Manufacturers did attempt to lobby against the bill on the grounds that compliance would be costly and that business should be free of regulatory burdens. However, Edwin Etherington, the president of the American Stock Exchange, estimated the annual compliance costs at approximately $\$ 1500$ to $\$ 3000$ for most OTC companies that were to be covered by the bill and Congress seemed to find this estimate compelling.

${ }^{9}$ The compliance date for firms that met the asset test and had between 500 and 750 shareholders was the last day of its first fiscal year to end after July 1, 1966.
} 
The structure and timing of the 1964 Securities Act Amendments provides a compelling setting to evaluate the impacts of mandatory disclosure laws on stock returns. This subsection details how we exploit the structure of the legislation to create multiple groups of OTC firms that were affected by the legislation to varying degrees and NYSE/AMEX firms that were all unaffected. It also explains how the legislation provides a natural way to divide the years 1963-1966 into two periods to examine the law's effects and perform validation exercises of our approach.

First, we explain how we classify firms so that we can exploit firm variation. We divide the OTC firms in our sample into four groups, based on their characteristics at the beginning of 1963 which precedes any serious discussion of the 1964 Amendments. The aim is to use ex ante information to categorize OTC firms into groups where we expect relatively large and small "treatment effects" of the disclosure requirements on stock returns as a means to check the validity of the results. ${ }^{10}$

To fix thoughts, we define the expected treatment effect for group $i$ as $t_{i}=t_{i}\left(\Delta P_{i}, \Delta D_{i}\right)$. Here, $\Delta P_{i}$ is the expected change in the fraction of OTC firms in group $i$ that comply with the mandatory disclosure requirements due to the 1964 Amendments. Some firms will not comply, because they fall below the asset or shareholder floors for endogenous or exogenous reasons. $\Delta D_{i}$ denotes the expected change in diversion that occurs among firms in group $i$ that are subject to the mandatory disclosure requirements specified by the 1964 Amendments. $\Delta D_{i}$ varies across groups due to differences in the initial levels of diversion. We assume that the treatment effect is increasing in the expected fraction of complying firms $\left(\partial t_{i} / \partial \Delta P_{i}>0\right)$ and in the reduction in diversion conditional on compliance $\left(\partial t_{i} / \partial \Delta D_{i}<0\right)$.

Each OTC firm in our sample is assigned a value for their likely $\Delta P$ and $\Delta D$ and these values are used to create the OTC groups. For simplicity, we assume that $\Delta P$ and $\Delta D$ take on two values, high and low. ${ }^{11}$ The interaction of $\Delta P$ and $\Delta D$ defines four independent categories of firms, which determine the OTC groups.

Measures of assets and number of shareholders in 1962 are used to assign firms to the high and low categories for $\Delta P$. We assign a high value of $\Delta P$ to firms with measured assets in 1962 exceeding $\$ 1$ million and more than 500 shareholders and to firms with measured assets exceeding

\footnotetext{
${ }^{10}$ We use pre-legislation information to assign firms to the OTC groups rather than ex-post compliance behavior for two reasons. First, compliance is conditional on size. Therefore, firms that eventually did comply would mechanically tend to have had higher returns in the past. Forming groups based on ex-ante variables avoids this problem. Second, some firms may manipulate their assets or shareholders so they do not have to comply with the law. The policy relevant treatment effect will account for such (likely unavoidable) manipulation rather than looking only at firms that comply.

${ }^{11}$ Note that high $\Delta D$ means a more negative number while high $\Delta P$ indicates a more positive number.
} 
$\$ 5$ million but no shareholder data. ${ }^{12}$ We assign all other firms to the low category for $\Delta P$.

Our expectation is that the 1964 Amendments induced larger reductions in diversion (i.e., $\Delta D$ ) among firms newly affected by all four types of disclosure, compared to firms that were only newly affected by the proxy and insider trading regulations. Consequently, firms that were not filing annual reports with the SEC by the beginning of 1963 (see the Data Appendix for further details) are assigned a high value for $\Delta D$ and firms that were filing annual reports by then receive a low value. SEC publications were used to determine which OTC firms were filing periodic reports as of the start of 1963 .

The first OTC group consists of firms assigned to the high category for $\Delta P$ and $\Delta D$. At the beginning of 1963, these firms were not filing annual reports with the SEC and were above the size cutoffs specified in the 1964 Amendments. Henceforth, we refer to these firms as the 0-4 group. The number before (after) the dash refers to the number of forms of disclosure that the firm was required to comply with before (after) the 1964 Amendments were in force. We use this same naming convention to denote the other groups. ${ }^{13}$

The second group consists of firms that were filing annual reports with the SEC by the start of 1963 and were above the 1964 Amendments' size cutoffs. The firms in this group were assigned to the high category for $\Delta P$ and low for $\Delta D$. The 1964 Amendments subjected these firms to two new disclosure rules - the proxy and insider transaction regulations. We label this group 2-4.

The third group is designated 0-0. It is comprised of firms that by the beginning of 1963 were not filing annual reports with the SEC and fell below the asset and/or shareholder floors of the 1964 Amendments. These firms were assigned to the low category for $\Delta P$ and high category for $\Delta D$. The fourth and final set of OTC firms is called the 2-2 group. By 1963, these firms were filing periodic reports with the SEC but fell below the 1964 Amendments' asset and/or shareholder floors. These firms are in the low category for $\Delta P$ and $\Delta D$. See the Data Appendix for a more detailed description of the precise rules used to assign firms to the different OTC groups.

If the mandatory disclosure requirements were valued by outside shareholders, then we expect the treatment effects to differ across OTC groups. In particular, our prediction is that the 0-4's treatment effect will be the largest, because these firms are in the high category for both $\Delta P$ and

\footnotetext{
${ }^{12}$ There are no cases where shareholder information is available but assets are not available. The subsequent results are insensitive to sensible changes in the asset cutoff used for firms with missing shareholder data.

${ }^{13}$ Some firms in our 0-4 group may have registered under the 1933 Act (if they made a small public offering after 1936). All firms that made a new or secondary offering (of equity or debt) were required to file a registration statement with the SEC under the 1933 Securities Act and send a prospectus to purchasers. The associated documents include a "Schedule A" that lists detailed financial information, including at least three years of balance sheet and income statement data, and descriptions of the firm's business, officers, costs of issuing the security, and intended use of any capital.
} 
$\Delta D$. By analogous reasoning, we expect the 2-2's treatment effect to be the smallest because its firms are in the low category for both $\Delta P$ and $\Delta D$. We predict that the 2-4's and 0-0's treatment effects are between the 0-4's and 2-2's effects. The ordering of these two groups' treatment effects depends on whether the effect of $\Delta P$ or $\Delta D$ on stock returns is larger.

We also create groups of NYSE/AMEX firms and use them to mitigate the possibility of confounding the effects of the 1964 Amendments with shocks to stock returns common to OTC and NYSE/AMEX firms. These 4-4 groups are constructed so that the distributions of the underlying firms' market capitalizations and the ratio of book value of equity to market capitalizations are similar to these distributions in the corresponding OTC group. We match these distributions because Fama and French [1992] demonstrate that average stock returns vary systematically with market capitalization and the book-to-market ratio. See the Data Appendix for further details on the construction of the $4-4$ groups.

Now we explain how we divide 1963-1966 into two periods so that our analysis can exploit time variation in regulatory status. ${ }^{14}$ Period 1 runs from January 1, 1963 through November 15, 1965. During this period, the 1964 Amendments were initially proposed, passed into legislation, and it was revealed which individual firms registered under the 1964 Amendments with the SEC. We assume that the full impact of the 1964 Amendments on stock returns occurs in this period. Data from this period is used to test the null hypotheses that the OTC groups had zero abnormal excess returns, relative to their corresponding size and book-to-market matched NYSE/AMEX (4-4) groups. A failure to reject the null would suggest that the disclosure requirements were not expected to produce information that was valued by outside shareholders (after accounting for compliance costs).

We also divide Period 1 into two subperiods to separately examine the stock returns of the OTC groups in the 85 weeks lasting from January 1, 1963 through August 24, 1964 (i.e., Period 1a) and the 64 weeks from August 25, 1964 through November, 15, 1965 (i.e., Period 1b). During Period 1a, the probability that a law extending the four disclosure requirements to OTC firms increased from some unknown level to one. ${ }^{15}$ Thus, this subperiod provides an opportunity to gauge the share of any overall Period 1 effect that is due to forward-looking asset markets' expectation of the law's value to shareholders.

\footnotetext{
${ }^{14}$ See Table I for an outline of key dates associated with the passage and implementation of the 1964 Securities Amendments, as well as a summary of the periods we define for our analysis.

${ }^{15}$ Although the Special Study was released on April 3, 1963, we suspect that its basic findings may have begun to permeate the investment community earlier. How much earlier is unknown, so the choice of January 1 as a beginning date has an element of arbitrariness. The choice of August 24, 1964 as an end date seems uncontroversial, as that is the date of the first issue of Barron's after Johnson signed the bill.
} 
During Period 1b, OTC firms above the size cutoffs were required to begin to comply with the Amendments' disclosure requirements. Here, we assess the share of any Period 1 effect that is due to the market's incorrect ex ante expectations about the fraction of firms that would comply or the average financial position revealed in the registration statements. Because the 1964 Amendments were the first imposition of disclosure requirements in three decades, it may be reasonable to expect that market participants updated their estimates of the impact of these disclosure requirements (in terms of $\Delta P$ or $\Delta D)$ during this subperiod.

Period 2 runs from November 15, 1965 through the end of 1966 and during these 58 weeks virtually no new information about the law or which firms would comply with its requirements was revealed. We use this period to assess the validity of our approach. Specifically, rejection of the null of zero abnormal excess returns for affected OTC groups in this period would invalidate our research design and any findings from Period 1.

Finally, firms' deadlines for complying with the new disclosure requirements were based on their fiscal year end and this provides an especially powerful test of whether shareholders valued the disclosure requirements. We implement an event study analysis with data from Period $1 b$ to test whether firms had abnormal excess returns in the weeks that news of their compliance with the disclosure requirements became known to market participants. We assume that, after the passage of the 1964 Amendments, the market's expectation of any individual firm complying was between zero and one and that this probability then increased to one or declined to zero upon news about a firm's decision to comply. ${ }^{16}$ Due to variation across firms in fiscal year ends, the first registrations under the 1964 Amendments were filed with the SEC in the fall of 1964 but initial filings continued through the end of October, 1965. Consequently, this event study allows us to exploit firm-level (rather than group-level) variation.

\section{DATA}

\section{IV.A. Data Sources}

We use the Center for Research in Security Prices (CRSP $\left.{ }^{\circledR}\right)$ database to calculate returns of NYSE/AMEX firms for the 1963-1966 period. We restrict the sample to those firms present in the first week of January 1963 and this sample of firms is intentionally not refreshed in later weeks. A corresponding electronic dataset of OTC firms did not exist for the period we study, as OTC (i.e., NASDAQ) firms are not available in CRSP until December 1972.

\footnotetext{
${ }^{16}$ Even if the market had the correct expectations about the percentage of firms in one of the OTC groups that would comply with the law, it is unlikely that the market had the correct expectations about each firm in the group.
} 
We therefore created the equivalent of the CRSP database for 1,196 OTC securities for the 1963-1966 period. The sample is comprised of securities that appeared in the January 7, 1963 issue of Barron's and were potentially affected by the 1964 Amendments. The bid and ask share prices for these firms were determined from Barron's weekly publications from the sample's four years. The relevant pages were photocopied and scanned in the U.S. and then converted to electronic files by Mascon Computer Services (P)Ltd. of India. ${ }^{17}$ We formed a panel data file of these securities by using their reported name to match firms across issues of Barron's. Just like the NYSE/AMEX sample, the panel of OTC firms is never refreshed with entrants to the Barron's OTC stock tables, because our goal is to estimate the impact of the imposition of mandated disclosure requirements on an existing set of firms.

The calculation of weekly OTC returns required the compilation of data on weekly bid and ask share prices, dividends, stock splits, mergers, name changes, liquidations, and moves from OTC to NYSE/AMEX. We also collected data on the firms' industries, financial and accounting positions in 1962 and 1966, as well as information on which firms filed reports with the SEC in each year of our sample, and the exact date that complying OTC firms filed with the SEC for the first time. The resulting database is derived from hand-entered information from eleven separate sources: Barron's, Standard and Poor's Annual Dividend Record, National Stock Summary (NSS), Directory of Obsolete Securities, Moody's Industrial Manual, Moody's Public Utility Manual, Moody's Bank and Financial Manual, Moody's Transportation Manual, Directory of Companies Filing Annual Reports with the SEC Under the Securities Exchange Act of 1934 (SEC Directory), U.S. SEC News Digest, and Security Owner's Stock Guide. We used the COMPUSTAT electronic files to obtain accounting information for the NYSE/AMEX firm and supplemented this with information from the four Moody's Manuals for NYSE/AMEX firms not covered in COMPUSTAT. The Data Appendix reviews our extensive data quality assurance procedures and provides some further details on the resulting data file.

\section{IV.B. Summary Statistics}

Table II reports summary statistics from our data file for each of the four OTC groups and the firms listed on the NYSE/AMEX. Panel A displays the number of firms in each of the groups in the first week of 1963 and their survival rate in our sample as of the last week of 1966 . The 0-4 group has 240 firms in the beginning of 1963 . This group is considerably smaller than the $2-4$

\footnotetext{
${ }^{17}$ Mascon double entered the security name and the bid and ask prices from each issue of Barron's. Mascon guarantees a 99.9 percent accuracy rate. The Data Appendix details the numerous data quality checks we undertook as a further precaution against transcription errors, as well as our extensive procedures to assign exit returns to firms that disappear from our sample.
} 
group, which initially has 738 firms, because many 1963 OTC firms had made a public offering in the previous twenty-seven years. The samples of 0-0 and 2-2 firms are substantially smaller, because Barron's selected the largest and most actively traded OTC firms for inclusion in their stock tables. CRSP lists 1,915 NYSE/AMEX firms that meet our sample requirements.

Survival rates vary across the different groups. The rates are roughly comparable among the 0-4, 2-4, and 4-4 groups and are even closer after matching on total market capitalization. ${ }^{18}$ This similarity in survival rates suggests that the OTC groups' attrition rates are due to genuine attrition, not insufficient data collection efforts on our part. The 0-0 and 2-2 groups have lower survival rates, because the 1964 Amendments' size cutoffs ensure that they are comprised of small firms. As will become evident below, these groups' small starting size and high attrition rates make meaningful inference difficult in parts of the subsequent analysis.

Panel B of Table II reports the percentage of firms that have complied with all four mandatory disclosure requirements as of July of the years 1963-1967. ${ }^{19}$ There was a dramatic increase in the percentage of OTC firms complying between 1964 and 1965 (the first year that many of these firms were required to file with the SEC). This suggests that managers of many firms considered the costs of non-compliance (the statutory penalties or costs of reducing firm assets or number of shareholders or going private) to be greater than the benefits. Further, our rules for assigning OTC firms to the groups appear to be validated by the larger increases in filing probabilities for the $0-4$ and 2-4 groups.

Panel C reports the means and medians (in parentheses) of a number of important variables as of the beginning of 1963, by OTC group. The number of firms with non-missing data is also reported. The Barron's and CRSP data are used to determine the share prices (calculated as the mean of the bid and ask prices for OTC firms) and the bid-ask spreads as a percentage of the share price from the first week of 1963 for the OTC groups. The entries indicate that the median share price among 0-4 and 2-4 firms is nearly three times greater than the median among the 0-0 and 2-2 firms. This is informative because share price is typically correlated with market capitalization and this variable is unavailable for many of the $0-0$ and 2-2 firms.

\footnotetext{
${ }^{18}$ For example, the median market capitalization of firms in the $0-4$ and $2-4$ groups would place those firms in the second quintile of market capitalization among NYSE/AMEX firms (where quintile 1 is comprised of the smallest firms). The survival rate of quintile 2 NYSE/AMEX firms is 81.2 percent between 1963 and 1966, which is in between the $0-4$ and 2-4 survival rates.

${ }^{19}$ Specifically, we consider an OTC firm to be in compliance with all four mandatory disclosure requirements if (1) the firm is in the 0-4 or 0-0 group and is included in that year's $S E C$ Directory or is acquired by a firm listed in that publication, or (2) the firm is in the $2-4$ or $2-2$ group and is included in the U.S. SEC News Digest in an issue prior to July of the year, or is acquired by a firm listed in that publication, or (3) the firm moved to the NYSE/AMEX, or was acquired by a firm on one of these exchanges prior to July of the year.
} 
Numerous theoretical studies have argued that bid-ask spreads reflect information asymmetry between insiders with private information and outside shareholders (see Madhavan [2000] for further background.). The bid-ask entries reveal that, after crudely controlling for size, firms that were already filing with the SEC at the start of 1963 had lower percentage bid-ask spreads than the firms that were free of SEC disclosure requirements. Specifically, the 2-4's (2-2's) percentage bidask spread is lower than the 0-4's (0-0's). We also explored this possibility more formally in a regression framework and found that after adjustment for the inverse of the share price, the bid-ask spread was about one percentage point lower for 1963 filers than non-filers. These findings are consistent with the possibility that the information provided through registration with the SEC and the periodic filings reduced information differences between outside investors and insiders.

The remainder of the table reports on a series of 1962 firm-level variables collected from various issues of the Moody's Manuals, COMPUSTAT, and the S\&P's Security Owner's Stock Guide. The mean (median) market capitalization (in millions of $1963 \$$ 's) for the $0-4$ and 2-4 groups are $\$ 44.6$ (\$9.1) and $\$ 26.5$ (\$10.4), respectively. The total market capitalizations of these two groups in $2005 \$$ 's are $\$ 66$ billion and $\$ 122$ billion, respectively.

The final row examines the percentage of shares outstanding held by institutions. ${ }^{20}$ These data are available for roughly half and two-thirds of the 0-4 and 2-4 firms, respectively. Conditional on non-missing data, the mean of this variable is roughly four percent in both groups. This demonstrates that institutions did not have a prohibition against holding shares of firms that were not registered with the SEC. Consequently, it is unlikely that the 0-4 firms' positive abnormal excess returns documented below are due to downward sloping demand curves for these stocks and an increase in buyers eligible to purchase them after the passage of the 1964 Amendments.

Market capitalization is available for less than thirty percent of the $0-0$ and $2-2$ firms. The accounting data are more likely to be non-missing and these variables confirm that the $0-0$ and $2-2$ firms are much smaller than the 0-4 and 2-4 firms (e.g., see assets).

Overall, Panel C paints a mixed picture on the extent of informational aysmmetries between insiders and outsiders. On the one hand, market capitalization and accounting data is available for virtually all 0-4 and 2-4 firms. The similarity in the availability of information in these groups of pre-1963 non-filers and filers suggests that private markets via third parties like Moody's produced much of the information that shareholders were likely to value. On the other hand, the finding that the bid-ask spreads were larger for non-filers undermines this view. One possibility is that these larger bid-ask spreads reflect an inability to set appropriate penalties for insiders that provided

\footnotetext{
${ }^{20}$ These calculations are based on data from institutional shareholders, including investment companies, fire, casualty and life insurance companies, pension funds and retirement systems.
} 
false information to the market.

\section{Empirical Methodology}

We construct time series of the equal-weighted portfolio returns for the OTC and NYSE/AMEX groups. This is denoted as:

$$
R_{g t}=\frac{1}{N_{g t}} \Sigma_{i=1}^{N_{g t}} R_{i g t}=\frac{1}{N_{g t}} \Sigma_{i=1}^{N_{g t}}\left(P_{i g t}-P_{i g, t-1}+D_{i g t}\right) / P_{i g, t-1}
$$

where $R_{g t}$ is the return for holding the group $g$ portfolio from the end of week $t-1$ to the end of week $t$. The return for each security in the portfolio, $R_{i g t}$, is calculated as the change in the splitadjusted price per share at the ends of week $t$ and $t-1$ (i.e., $P_{i g t}-P_{i g, t-1}$ ), plus any split-adjusted dividends paid between the price observations (i.e., $D_{i g t}$ ), all divided by the split-adjusted price at the end of week $t-1$. $P_{i g t}$ is equal to the mean of the bid and ask prices for a security in week $t$. $N_{g t}$ is the number of firms in group $g$ in week $t$.

We model the returns using a standard four-factor model:

$$
R_{g t}-R_{f t}=\alpha_{g}+\beta_{1 g}\left(R_{m t}-R_{f t}\right)+\beta_{2 g} S M B_{t}+\beta_{3 g} H M L_{t}+\beta_{4 g} M O M_{t}+\varepsilon_{g t}
$$

where $R_{f t}$ is the return on a risk-free asset, which is measured as the Treasury bill rate. This equation controls for the difference between market and risk-free returns, the size and book-tomarket factors of Fama and French [1993], and a momentum factor based on Carhart [1997]. The market return, $R_{m t}$, is measured as the value-weighted CRSP return using all NYSE and AMEX firms present in weeks $t$ and $t-1$. The three factors are measured as the difference in the returns of portfolios of small and large stocks (SMB), value and growth stocks (HML), and stocks with high and low returns over the two to twelve months prior to the current date (MOM). ${ }^{21}$ The $g$ subscript on the parameters underscores that the effect of the factors can vary across groups. $\varepsilon_{g t}$ is the unobserved determinant of group g's return.

$\alpha_{g}$ measures the abnormal excess returns specific to group $g$. The appeal of this measure of abnormal returns is that it has been purged of any covariance of group g's return with the overall

\footnotetext{
${ }^{21}$ Kenneth French generously provided us with the SMB and HML daily factor series from 1963-1966.

Using daily return data, we calculated the weekly momentum series based on the formulas on French's web page (http://mba.tuck.dartmouth.edu/pages/faculty/ken.french/data_library.html.)

There are two important consequences of the fact that the market return and three factors are calculated with NYSE and AMEX data. First, incomplete market capitalization and accounting data for the OTC firms do not pose a problem for estimation. Second, all the listed firms are unaffected by the 1964 Amendments so the factors are not a function of the law.
} 
market and the three factors. This is important because a group may have high or low returns in the examined period simply because of its risk relative to the market or because it is disproportionately comprised of small, value, and/or high momentum firms. ${ }^{22}$ The fitting of equation (2) is considered a standard method to test for abnormal excess returns.

It is tempting to interpret the estimated $\alpha_{g}$ 's from Period 1 for the OTC groups as the effect of the 1964 Amendments. The credibility of this interpretation rests on the assumption that the four-factor model has adequately adjusted for all systematic determinants of stock returns, except the 1964 Amendments. This assumption is invalid if there are shocks to the returns of OTC and NYSE/AMEX firms of the size or market to book ratio typical in one (or all) of the OTC groups that are not fully controlled for in equation (2). In this case, the estimated $\alpha_{g}$ would capture the effect of the 1964 Amendments and these shocks.

To mitigate the possibility of confounding the effects of the 1964 Amendments with unrelated shocks to stock returns, we difference versions of equation (2) for each OTC group and its corresponding size- and book-to-market-matched 4-4 group. An example of special interest is the difference between the 0-4 group and its corresponding 4-4 group, which becomes:

$$
\begin{aligned}
R_{0-4, t}-R_{4-4, t}^{0-4}= & \left(\alpha_{0-4}-\alpha_{4-4}\right)+\left(\beta_{1,0-4}-\beta_{1,4-4}\right)\left(R_{m t}-R_{f t}\right)+\left(\beta_{2,0-4}-\beta_{2,4-4}\right) S M B_{t} \\
& +\left(\beta_{3,0-4}-\beta_{3,4-4}\right) H M L_{t}+\left(\beta_{4,0-4}-\beta_{4,4-4}\right) M O M_{t}+\left(\varepsilon_{0-4, t}-\varepsilon_{4-4, t}\right),(3)
\end{aligned}
$$

where $R_{4-4, t}^{0-4}$ equals the return of the 0-4 matched 4-4 group in week $t$. The differencing removes all shocks common to the 0-4 and matched 4-4 group from equation (3), so such shocks cannot cause the model to be specified incorrectly. The estimated $\beta$ 's measure the difference in the loadings between the 0-4 and matched 4-4 groups.

The parameter of interest is $\left(\alpha_{0-4}-\alpha_{4-4}\right)$, which is the difference in the abnormal excess returns between the 0-4 and the matched 4-4 group. We test the null hypothesis that this parameter is equal to zero for all OTC groups and interpret a rejection of the null in Period 1 as evidence that the 1964 Amendments affected stock returns. This test is also implemented in Period 2 as a check on the validity of the model. We also report estimates of $\alpha_{g}$ for the OTC groups from the estimation of equation (2), though these results are not our focus because they are less likely to be reliable. To account for the possibility of unequal variances across weeks, we present standard errors calculated with the Eicker-White formula that allows for heteroscedasticity of an unspecified form throughout the paper.

\footnotetext{
${ }^{22}$ In the cross-section of U.S. stocks, it is well documented that the $\alpha$ 's from a four-factor model are much more tightly distributed around zero than the $\alpha$ 's from the basic CAPM using $R_{m t}-R_{f t}$ as the only factor.
} 
Four other features of our approach merit highlighting. First, as equation (1) indicates, a portfolio's weekly return is calculated as the simple average across the returns of firms in that portfolio. This is equivalent to a portfolio that is rebalanced every week to ensure an equal weighting across all firms. The advantage of this approach is that returns can be calculated when the number of shares outstanding is unknown. The primary shortcomings are that such a portfolio would involve large transactions costs, and it does not mimic the buy-and-hold portfolio strategies that many investors utilize.

We probe the robustness of our results to alternative portfolio construction strategies in a few ways. We present results from a buy-and-hold strategy with equal initial weighting. This approach begins by putting an equal dollar value in each stock in the relevant OTC or NYSE/AMEX group and then assumes that no trades are made subsequently. In the calculation of the portfolio's return from date $t$ to $t+1$, stock $i$ 's weight equals (value of holdings of stock $i$ at $t$ )/(total value of portfolio at $t$ ). Consequently, the weight on a particular stock evolves over time based on its returns relative to the rest of the portfolio. ${ }^{23}$ We also implement a value-weighted buy-and-hold strategy, where each firm's initial weight is equal to the firm's share of the portfolio's total market capitalization at the beginning of the relevant period. ${ }^{24}$ The weights then evolve in the same way as in the buy-and-hold with equal initial weighting approach.

Second, the estimated abnormal excess return from equation (3) may be biased by industryspecific shocks that are unrelated to the law if there are differences in the industry composition of the OTC and 4-4 groups. To probe this possibility, we also present results where the weekly returns for the companion 4-4 groups are calculated with the week-specific 2-digit SIC industry weights of the relevant OTC groups. ${ }^{25}$

Third, shocks specific to the OTC market that are unrelated to the law remain a potential source of confounding. To probe the robustness of the results to this possibility, we test whether the 0-4 group, which we suspect was the most affected by the legislation, had larger abnormal excess

\footnotetext{
${ }^{23}$ We use this approach to construct buy-and-hold portfolio returns rather than the approach of averaging firm level buy-and-hold time series used by Loughran and Ritter [1995] and others. The statistical properties of the alternative approach are less well understood. We want to ensure that any differences in results between our equal-weighted portfolios and portfolios designed to mimic a buy-and-hold strategy are not driven by such issues.

${ }^{24}$ This approach requires data on the shares outstanding to calculate firms' market capitalization. Because this variable is missing for 81 percent and 59 percent of the 0-0 and 2-2 firms, respectively, the results of the value-weighted buy-and-hold strategy are not fully comparable to those from the other strategies considered for these groups.

${ }^{25}$ We determined the primary industry for all firms in the 0-4, 2-4, and 2-2 groups. We were unable to ascertain the industry for 24 firms in the 0-0 group. These firms are omitted from the calculation of industry adjusted returns, so the 0-0 industry matched estimates are not comparable to results from the other portfolio construction methods.

We also attempted to match OTC firms to NYSE/AMEX firms on industry and market capitalization. Specifically, we used all firms in the smallest six market capitalization deciles to calculate the 4-4 industry index returns. The results from this approach are similar to the industry only matched returns presented below.
} 
returns than the other OTC groups. The law also potentially affected the other groups, including the 0-0 and 2-2 groups because some of their firms grew large enough to have to comply. Therefore, any difference in returns between the 0-4 group and the other OTC groups is likely to understate the total effect of the mandatory disclosure requirements. Consequently, it is best conceived as a robustness check of the qualitative results.

Fourth, a drawback of our comparison of returns during Periods 1 and 2 is that there is no firm-level variation in the timing of these periods within the OTC groups. Recall, however, there are firm-level differences in the timing of the resolution of the uncertainty surrounding which firms would comply with the 1964 Amendments that are largely due to variation in fiscal year ends. We exploit this variation to implement an event-study analysis in the weeks that news of firms' initial compliance became known to market participants.

\section{Results}

$\underline{\text { VI.A. Firm-Level Event Study of Initial Filing }}$

The analysis begins with a firm-level event study of the effect of the announcement that OTC firms were officially in compliance with the 1964 Amendment's new mandatory disclosure requirements on stock returns. We obtained the precise dates that the SEC announced that pre-legislation non-filing firms had fulfilled the registration requirement and pre-legislation filers had fulfilled the proxy and insider holdings/trades requirements for the first time. These official filing dates were collected from the daily issues of the SEC News Digest, which, as a matter of policy, published them 60 days after the SEC received the filings. This delay means that the news of a firm's filing with the SEC may have become known to market participants as early as 60 days preceding the announcement or any time in between. For the remainder of this section, we refer to these firms as "new filers" and the dates of the announcement in the SEC News Digest as the "filing dates".

We use these filing dates as the basis of a firm-level event study of the effect of choosing to become a new filer. Specifically, we estimate a firm-level version of equation (3). The dependent variable is a firm's weekly return minus that week's average return for the firms in the size and book-to-market cell of NYSE/AMEX that the OTC firm would have belonged to at the beginning of 1963. This model is estimated with data from the 64-week-long Period 1b, which covers the weeks when most affected OTC firms were required to file with the SEC. The standard errors are clustered by week to account for the likely covariance in return residuals across firms within a week.

The substantive difference with equation (3) is that we add an indicator variable that equals one during the "event window" and its associated parameter is the focus of these regressions. Due to 
the uncertainty surrounding the exact date that the market learned that a firm had become a new filer, we define the event window so that it lasts for ten weeks. Specifically, it begins eight weeks prior to the SEC filing date and ends one week after this date. Week zero in event time is defined to include the SEC filing date. The event window is extended one week beyond the filing date to allow the information to disseminate. Thus, the parameter on the event window indicator tests for abnormal excess returns in the ten-week period when news of a firm's decision to file became known in the marketplace.

Each column of Table III presents the results from a separate regression. We report the parameter estimates and standard errors on the event window indicator and the constant, along with the R-squared statistics. Columns (1)-(3) reports results for the 0-4 group and (4)-(6) contain the analogous findings for the 2-4 group. In columns (1) and (4), the sample is limited to new filers with filing dates during Period $1 \mathrm{~b}$ and the estimates are not adjusted for the market return or any of the three other return factors. Thus, this specification examines the differenced raw returns. Columns (2) and (5) report the results from the same sample after adjustment for the full four factor model. Columns (3) and (6) also present adjusted results but the respective samples now also include 0-4 and 2-4 firms that moved to the NYSE/AMEX, filed after the end of Period 1b, or never filed. ${ }^{26}$ The specification and sample details are reported at the bottom of the table. ${ }^{27}$

The results provide striking evidence of positive abnormal excess returns for 0-4 and 2-4 filers during the ten-week event window. The 0-4 filers have a positive abnormal excess return of about 0.35 percent per week during this event window, or a cumulative return of roughly 3.5 percent. These estimates would be judged statistically significant at conventional levels. This result is not affected by adjustment for the four factors and the change in sample. The 2-4 firms also experience a statistically significant positive abnormal excess return of approximately 0.35 percent per week for a cumulative return of 3.5 percent during the event window. Similarly, the 2-4 estimates are stable across the different specifications. ${ }^{28}$

Figure 1 presents the 0-4 and 2-4 results graphically. These figures are derived from the column

\footnotetext{
${ }^{26}$ There are 215 (693) 0-4 (2-4) firms in the sample at the beginning of Period 1b. 145 (417) of these firms have a filing date in this period, while 13 (24) others have a filing date between the end of Period $1 \mathrm{~b}$ and the end of 1967. 30 (168) moved to the NYSE/AMEX in 1963, 1964, 1965 or 1966 where they were subject to all four mandatory disclosure requirements. The remaining 27 (84) firms either do not have a filing date by the end of 1967 or were acquired by a firm without a filing date by 1967 .

${ }^{27}$ We did not implement the event study analysis for the 0-0 and 2-2 groups, because they included too few new filers in Period 1b.

${ }^{28}$ When we fit the firm-level version of equation (2) that adjusts for the market and three other factors, the cumulative event window returns are 3.2 percent and 3.3 percent for the $0-4$ and $2-4$ registrants, respectively. Recall, this approach does not use the 4-4's as a comparison group.
} 
(2) and (5) specifications that adjust for the four factors, except that we have dropped the event window indicator. The average residuals are then calculated for each event week ranging from twenty weeks before registration through 10 weeks after registration. ${ }^{29}$ These average residuals are considered the average abnormal excess return in a week, where the precise week is denoted by its distance from the week with the filing date. The cumulative average abnormal excess returns are plotted against the event week for the 0-4 and 2-4 groups. The vertical lines are drawn at event weeks -9 and +1 .

The figure provides an even more demanding test of the hypothesis that initial filing is associated with abnormal excess returns, because it is possible to observe the pre- and post-event window trends. The flat 0-4 and 2-4 lines between week -20 and week -9 suggest there are not abnormal excess returns in this period. During the event window, the cumulative abnormal excess return lines turn upward, graphically demonstrating the source of the results in Table 6 . These lines are flat from week 1 through week 10 .

We hoped to implement a similar analysis for the firms that chose not to comply with the disclosure requirements. In these cases, the prediction is that confirmation that a firm would not comply with the disclosure requirements should lead to negative abnormal excess returns as the probability of compliance changes from the market's ex-ante estimate to zero. The practical difficulty with implementing this analysis is that we were unable to isolate the precise dates that this information became public. For example, it was not uncommon for the SEC to grant firms extensions that delayed their statutorily required filing date (sometimes even beyond the end of Period $1 \mathrm{~b})$. We were unable to determine the identities of the firms that received these extensions.

Overall, Table III and Figure 1 provide strong evidence that the market rewarded firms that complied with the mandatory disclosure requirements specified by the 1964 Amendments. However, due to the forward looking nature of asset markets, it is possible that OTC firms had abnormal excess returns in the period that the legislation was debated and ultimately passed. To estimate the full effect of the 1964 Amendments on stock returns, the next section tests for abnormal excess returns among the OTC groups over the entire Period 1.

\section{$\underline{\text { VI.B. Period } 1}$}

We begin with a graphical analysis of the unadjusted returns by OTC group. Figures $2 \mathrm{a}$ and $2 \mathrm{~b}$ plot the cumulative average returns for the four OTC and matched NYSE/AMEX groups,

\footnotetext{
${ }^{29}$ The distribution of filing dates is such that virtually all filers have observations for each of these event weeks. This is not the case when the graph is expanded beyond $t=-20$ or $t=10$. Further, the filing dates for the $0-4$ and 2-4 firms were distributed throughout Period 1b.
} 
respectively, over the course of our sample. Each data point represents a week's return for a group added to the sum of the return in all previous weeks. The first vertical line denotes the end of Period 1a and the second marks the end of Period 1b.

Figure 2a demonstrates that, by the end of Period 1, the cumulative returns (over the risk-free rate) for the $0-4,2-4,0-0$, and $2-2$ groups were $55.9,43.8,38.0$, and 31.7 percent, respectively. These values for the raw return data are consistent with investors valuing the disclosures mandated by the 1964 Amendments, because the groups most likely to have to make new disclosures (0-4 and 2-4 firms) have the highest returns. Further, the raw returns are consistent with the predictions that the 0-4's would have the largest returns and the 2-2's would have the lowest returns in this period. In contrast, Figure $2 \mathrm{~b}$ shows that these differences in returns are not evident in the three sets of NYSE/AMEX comparison firms with matching size and book-to-market characteristics.

Figures $3 \mathrm{a}$ and $3 \mathrm{~b}$ depict the unadjusted cumulative returns for the $0-4,2-4$, and their matched 4-4 groups. Figure 3a reveals that the 0-4 group's cumulative return exceeds the matched 4-4's returns by 7.8 percent over the course of Period 1. Notably, the 0-4's excess returns first become apparent in mid-1964 when the legislative antecedents of the 1964 Amendments gained momentum in Congress and increase steadily for the remainder of the period. Therefore, the subsequent results will not be sensitive to reasonable changes in the start and end dates of the event window. From Figure $3 \mathrm{~b}$, it is evident that the 2-4 group and its matched 4-4 group had virtually identical raw returns in this period..$^{30}$

We now turn to our statistical analysis of the Period 1 stock returns. Table IV presents estimates of the abnormal excess returns for the 0-4 group in the first panel and the subsequent panels report results for the 2-4, 0-0, and 2-2 groups. ${ }^{31}$ Within a panel, we report estimates of $\alpha$, its standard error (in parentheses), and the R-squared statistic from the fitting of two versions of equation (2) and six variants of equation (3). We also report p-values from separate tests that the 0-4's estimated $\alpha$ is equal to the estimated $\alpha$ 's for the other OTC groups within a specification (i.e.,

\footnotetext{
${ }^{30}$ The 0-0 and 2-2 groups underperformed their NYSE/AMEX comparison group but due to the small size of the 0-0 and 2-2 groups, their returns are estimated imprecisely. This makes a graph comparing their returns with their matched 4-4 group less informative, so it is not presented here. The imprecision of comparisons between these groups is demonstrated in Table IV below.

${ }^{31}$ Period 1 spans 149 weeks, but the regressions only include 148 observations because the OTC and NYSE/AMEX stock returns are not comparable for the week of John F. Kennedy's assassination. OTC trading was suspended immediately upon the news that Kennedy had been wounded, but it continued for at least half an hour on the NYSE and AMEX (Wall Street Journal, November 27, 1963). As a result, NYSE/AMEX firms had large declines in that week while the returns of OTC firms were in line with a typical week. Consequently, we drop prices from the assassination week and treat the returns from the week before the assassination to the week after as a single observation.
} 
within a column). ${ }^{32}$

In columns (3)-(7) the 4-4 groups are constructed, as described above, so that the distributions of the underlying firms' market capitalizations and ratio of book to market are similar to the distribution of these variables in the corresponding OTC groups. In column (8), we use an industrymatched 4-4 group as the comparison but do not do any size or book to market matching due to sample size issues. The table also explores the sensitivity of the results to alternative portfolio construction rules. In all columns, except (6) and (7), we assume that investors in our constructed portfolios rebalance their holdings every week to keep them equally weighted across all securities. Column (6) reports the results from a buy-and-hold strategy with equal initial weighting. In column (7), the portfolios are based on a value-weighted buy-and-hold strategy. ${ }^{33}$ The specification details for each column are summarized at the bottom of the table.

We begin with the equation (2) specifications. The unadjusted entries in column (1) demonstrate that the $0-4$ 's had a mean weekly return (above the risk-free rate) of 0.378 percent over the 149 week period. Notably, the null hypothesis of equal returns for the 0-4 and 2-4 groups can be rejected at the two percent level. In the case of the smaller 0-0 and 2-2 groups, the analogous nulls can be rejected at the 15 and 10 percent levels, respectively, reflecting the imprecision of our estimates of these groups' returns. Overall, the raw data reveal that the differences in the returns of the group expected to have the largest treatment effect and the other OTC groups are statistically distinguishable at reasonable confidence levels.

In column (2), the OTC groups' returns are adjusted with the standard four factor model, which is considered a robust method for detecting abnormal excess returns. The entries indicate that the 0-4 and 2-4 groups had average abnormal excess weekly returns of 0.187 percent and 0.095 percent, respectively. These estimates imply cumulative abnormal excess returns of 27.7 percent and 14.1 percent and are statistically and economically significant. In contrast, the point estimates for the 0-0 and 2-2 groups are smaller and statistically insignificant. Appendix Table 2 reports the estimated $\beta$ 's from fitting equation (2) for the four OTC groups and three corresponding 4-4 groups for Period 1 (as well as Period 2).

Columns (3) through (8) use the matched 4-4 groups as "control" groups to avoid confounding the effect of the law with shocks that were unrelated to the 1964 Amendments. The column (3) entry for the 0-4 group is not adjusted for any of the four return factors and it indicates a weekly

\footnotetext{
${ }^{32}$ These tests are conducted by differencing the dependent variables, estimating equation (3), and testing whether the $\alpha$ of the differenced equation is significant.

${ }^{33}$ We drop one 0-4 firm (Royal Dutch/Shell) from the value weighted regressions, because it is 21 times larger than the next biggest firm and accounts for 57 percent of that group's total market capitalization at the beginning of the sample.
} 
abnormal excess return of 0.053 percent. This is the statistical summary of Figure 3a and it underscores that the Period 1 differences between the 0-4's and their corresponding 4-4 group in that figure are not statistically meaningful. However, the nulls that the $0-4$ 's returns are equal to the other OTC groups' returns (after subtracting the matching 4-4 control group returns from each of the OTC groups' returns) can all be rejected at the 10 percent level, further underscoring the differences in returns across OTC groups.

The point estimates in the remaining columns range between 0.078 and 0.149 percent, which imply cumulative returns ranging between 11.5 percent and 22.1 percent. ${ }^{34}$ The CAPM estimate would be judged to be statistically significant at the 11 percent level, while two of the four-factor estimates are significant at the one percent level or better, one at the four percent level, and one at the nine percent level. The stability of the point estimates across the different specifications is reassuring. However, the difference between these results and the unadjusted estimate in column (3) underscores that the validity of ascribing the difference in returns between the 0-4 group and its matched 4-4 group to the 1964 Amendments rests on the validity of the standard model for stock returns that adjusts for the market return and three factors. ${ }^{35}$ This contrasts with the findings from the event study and the comparisons of returns across the four OTC groups, neither of which hinge on whether we control for the four return factors.

We now turn to the results of fitting equation (3) for the 2-4 group reported in columns (3) through (8) of the second panel. The factor-adjusted point estimates range from 0.013 to 0.057 percent, which imply a cumulative abnormal excess return of 1.9-8.4 percent. ${ }^{36}$ Although these estimates are all in a relatively tight range, none of them differs statistically from zero at the ten percent level. Overall, the 2-4's findings provide modest support for the view that investors valued

\footnotetext{
${ }^{34}$ The estimates of the factor loadings (i.e., the $\beta$ 's) will be biased if the securities of OTC firms are less likely than those of NYSE/AMEX firms to be traded between weekly price observations. In this case, the estimated $\alpha$ 's are likely to be biased. We suspect that "stale" OTC prices are unlikely to be a source of bias, because Barron's only includes the most heavily traded OTC firms. Nevertheless, we also estimated models for two-week and four-week returns where this issue is much less relevant. The 0-4's estimated $\alpha$ (standard error) from specifications that use the matched 4-4's as controls and adjust for the market and three factors are 0.180 (0.080) and 0.418 (0.110) for the twoand four-week returns, respectively. When these estimates are divided by two and four, they are nearly identical to the estimates in column (5). We conclude that these results are not due to stale OTC prices.

${ }^{35}$ Among the different factors, the momentum factor has the least influence on the estimated $\alpha$. The equation (3) estimates of $\alpha$ and its standard error (in parentheses) from a specification that weights the firms equally and adjusts for the market return and the two Fama-French factors (but not the momentum, factor) are: 0.119 (0.045), 0.039 $(0.041),-0.044(0.096)$, and $-0.124(0.112)$ for the $0-4,2-4,0-0$ and $2-2$ groups, respectively. These estimates are very similar to those in column (5) that are adjusted for all four return factors. The null hypothesis that the parameter on the momentum factor is equal to zero cannot be rejected for any of the OTC or NYSE/AMEX groups in Period 1 (see Appendix Table 2).

${ }^{36}$ In five of the six specifications reported in columns (3) - (8), the null that the estimated $\alpha$ 's for the $0-4$ and $2-4$ groups are equal is rejected at the seven percent level or better.
} 
the introduction of proxy and insider trading disclosure requirements for firms that were already registered with the SEC and filing periodic reports. However, the imprecision of these estimates tempers the strength of any conclusions.

The third and fourth panels report the results for the 0-0 and 2-2 groups. In columns (3) through (8), all of the estimated $\alpha$ 's for these groups are negative and are smaller than the 0-4 and 2-4 groups' estimated $\alpha$ 's. At least partially due to the small sample sizes for these groups, the $0-0$ 's and 2-2's standard errors are generally more than twice as large as in the first two panels. This imprecision is evidenced by the fact that only three of the twelve estimates have an associated t-statistic greater than one.

Table V presents the results from fitting equations (2) and (3) in Periods 1a and 1b separately. We only report the results for the 0-4 and 2-4 groups, because the estimated $\alpha$ 's for the 0-0 and 2-2 groups in these subperiods are even more poorly determined. The intent here is to assess whether the Period 1 abnormal excess returns were concentrated in the weeks that the law was debated and passed (Period 1a) or the weeks when firms' compliance uncertainty was resolved and information about their financial position was revealed (Period 1b).

The results suggest that the 0-4's had positive abnormal excess returns in both subperiods but the bulk of them occurred while the law was debated and signed into law. The preferred Period 1a estimates in columns (4) through (8) are in a relatively narrow range and imply a cumulative abnormal excess return ranging from 8.5 percent to 14.0 percent. Two of these five estimates statistically differ from zero at the five percent level, the other three only at the fifteen percent level.

The point estimates from the shorter Period $1 \mathrm{~b}$ are generally smaller, more sensitive to changes in specification, and less likely to statistically differ from zero. However, they jointly seem to suggest that the 0-4's had positive abnormal excess returns in this subperiod too. For example, the estimate from the equal weighted four-factor model in column (5) implies a cumulative abnormal excess return of roughly 6.8 percent. It appears that initial filing announcements cannot account for all of the abnormal excess returns in this subperiod. ${ }^{37}$

The 2-4 results fail to provide convincing evidence of abnormal excess returns in either subperiod. The Period 1a point estimates are all positive, although it is only possible to reject a zero at conventional levels in one of the specifications. The Period $1 \mathrm{~b}$ estimates are sensitive to changes in the specification and are poorly determined.

\footnotetext{
${ }^{37}$ The largest difference between the Periods 1a and $1 \mathrm{~b}$ estimates in columns (4) through (8) occurs in the valueweighted buy-and-hold specification, column (7). In this specification, the abnormal excess returns are concentrated in Period 1a. Because there was less compliance uncertainty surrounding large firms, it is not surprising that these Period $1 \mathrm{~b}$ returns, which weight firms according to their size, are smaller.
} 
Overall, the Period 1 results suggest that the mandatory disclosure requirements introduced by the 1964 Amendments increased market participants' valuations of the 0-4 firms by 11.5-22.1 percent. There is little evidence that the Amendments affected the stock returns of the other OTC groups in this period.

\section{$\underline{\text { VI.C. Period } 2}$}

Recall, Period 2 is after the law has passed and the vast majority of complying firms have begun to file with the SEC. Consequently, our expectation is that the OTC groups will have zero abnormal excess returns in this period. If this null hypothesis is rejected by the data, it raises the possibility that our research design and/or the four-factor model is invalid here, which would undermine the credibility of the results from Period 1.

Table VI is structured identically to Table IV and reports the Period 2 results. The table provides little evidence of abnormal excess returns for any of the OTC groups. For example, none of the 32 estimates would be judged to be statistically different from zero at the ten percent level. It is notable that even the less robust equation (2) specification fails to find evidence of abnormal excess returns. Overall, the findings from this 58-week period support the validity of our approach and lend credibility to the hypothesis that the estimated effects in period 1 are due to the 1964 Amendments.

\section{$\underline{\text { VI.D. Operating Performance }}$}

As we discussed in Section II, our hypothesis is that mandatory disclosure laws bind managers to focus more on maximizing shareholder value. The evidence of positive abnormal excess returns for the 0-4 group in this period is consistent with this hypothesis but fails to shed light on exactly why market participants were willing to pay more for an ownership stake. This subsection explores one channel by testing whether OTC firms experienced improvements in operating performance relative to 4-4 firms between 1962 and 1966.

Table VII reports the results of four firm-level operating performance regressions. In columns (1) and (2), the dependent variable is the change in net income (profits) between 1966 and 1962, normalized by 1962 market capitalization. We normalize by market capitalization here, because income can be zero or negative. In columns (3) and (4), the dependent variable is the percentage change in sales between 1966 and 1962. Both net income and sales growth are considered important measures of operating performance, although net income is more closely related to stock returns.

The starting sample includes all 2,893 0-4, 2-4, and 4-4 firms present in the first week of 1963 . In columns (1) and (3), the sample is restricted to firms with known values for the dependent variable, 
which reduces the working samples to 2,408 and 2,331, respectively. Although the survival rates for the 0-4 and 2-4 OTC groups and the 4-4 group are similar, sample selection concerns may still be valid. ${ }^{38}$

Columns (2) and (4) address this sample selection issue by assigning the 50th and 10th percentiles of the dependent variables to firms with missing values for the dependent variables. Specifically, firms with missing values that exit for "negative" reasons (for NYSE/AMEX firms: liquidation or delisting; for OTC firms: liquidation or exit from our sample with a price less than \$2) are assigned the 10th percentile of the dependent variable among firms in their group (i.e., 0-4, 2-4, and 4-4). Firms with missing values that exit for more "neutral" reasons (for NYSE/AMEX firms: mergers; for OTC firms: mergers, name changes, exit from our sample with a price above $\$ 2$, and moves to CRSP) are assigned the 50th percentile of the dependent variable for their group.

We report the parameter estimates and standard errors (in parentheses) on indicator variables for 0-4 and 2-4 status. The excluded category is 4-4 firms. The regression also adjusts for the log of 1962 assets to account for differences in growth related to size, and for one-digit industry dummies. Due to concerns about outliers (especially data entry errors), we deleted observations that were in the top and bottom one percent of the dependent variable. The subsequent results are not sensitive to reasonable alternatives (e.g., two and five percent rules). ${ }^{39}$

The results indicate that 0-4 firms had the largest improvements in the two measures of operating performance. Specifically, the 0-4 firms' change in net income relative to initial market value was about 0.030-0.038 larger than the 4-4's. The mean of the dependent variable for 4-4 firms is 0.086, so the $0-4$ 's increase in this measure of income growth was 35-44 percent larger than the 4-4's. The 2-4 firms' point estimates are roughly a third as large as the 0-4's and would not be judged to be statistically significant by conventional criteria.

The sales growth results indicate that $0-4$ firms' total sales increased by a statistically significant 84-109 percent more than the unaffected 4-4 firms. The 2-4 firms had smaller relative increases in sales growth (i.e., 16-17 percent) and these estimates border on statistical significance at the five percent level. To put these numbers in context, the mean sales growth of 4-4 firms was roughly seventy percent, so the 0-4 firms' sales increase appear quite large. To investigate this further, we

\footnotetext{
${ }^{38}$ More than half of the firms with missing value of the dependent values are firms that were involved in mergers between 1962 and 1966. We do not use operating performance data for 1966 for firms involved in mergers because these data may not be comparable to the 1962 numbers.

${ }^{39}$ An alternative adjustment for survivorship bias would be a Heckman selection model (Heckman [1979]). This approach is not attractive in our setting because survival is directly related to performance, which makes it difficult to identify a valid exclusion restriction. Furthermore, identification from functional form alone is problematic because the 0-4 and 2-4 dummies are indicator variables (making identification off of non-linearities impossible) and theory provides little guidance on the functional form for log assets in either equation.
} 
estimated median regressions on the column (3) and (4) samples. They produced 0-4 indicator point estimates of 0.087 and 0.174 , respectively, both of which are statistically significant. It is evident that the $0-4$ conditional mean results in Table VII are heavily influenced by the top part of the percentage sales growth distribution. ${ }^{40}$

Overall, these results provide evidence that as soon as one year after most firms' compliance deadlines, the operating performance of 0-4 (and to a lesser degree 2-4) firms had improved, relative to 4-4 firms. These findings are consistent with the hypothesis that the mandatory disclosure requirements caused managers to more directly focus on maximizing shareholder value. ${ }^{41}$

\section{INTERPRETATION}

Based on the varied evidence presented in this paper, we conclude that investors valued the mandatory disclosure requirements imposed on 0-4 firms by the 1964 Amendments. We now try to put these numbers in some context. The estimates of the cumulative abnormal excess returns in Period 1 for the 0-4 firms ranged from 11.5 to 22.1 percent. Among the 236 0-4 firms with non-missing market capitalization data, the total market capitalization was $\$ 4.5$ billion (1963\$). These results imply that the 1964 Amendments created $\$ 0.5$ to $\$ 1.0$ billion (1963\$) or $\$ 3.2$ to $\$ 6.2$ billion $(2005 \$)$, of value for stockholders. ${ }^{42}$ These numbers understate the total increase in market capitalization associated with the legislation, because our sample only includes a quarter of the nearly 900 firms that filed with the SEC for the first time after passage of the 1964 Amendments (although it probably has many of the largest ones). As the conceptual framework highlighted, these numbers are an upper bound on the welfare gain associated with these mandatory disclosure regulations, because at least part of the gain in market capitalization reflects a transfer of insiders' resources to outside shareholders.

\footnotetext{
${ }^{40}$ The 2-4 point estimates from the median sales growth regressions are qualitatively similar to the ones in Table VII. Further, median regression has little effect on the point estimates for the $0-4$ and $2-4$ indicators in net income regressions.

${ }^{41}$ We considered studying alternative outcome variables to determine the mechanism for the 0-4's Period 1 abnormal excess stock returns. One potential mechanism is that the mandatory disclosure requirements might affect the liquidity of firms' shares, which is thought to be reflected in bid-ask spreads. We could not investigate this possibility in a meaningful way because there are not separate bid and ask prices for 4-4 firms and a substantial fraction of the 0-4's move to the NYSE/AMEX. Although our theoretical framework does not provide a clear prediction about volatility, this may be a relevant outcome variable. Ferrell [2004] finds evidence of a reduction in volatility among OTC firms after the 1964 Amendments are in force. We discuss the Ferrel paper in further detail in Section 7.

${ }^{42}$ To avoid potentially overstating the effects, this calculation excludes the one 0-4 firm, Royal Dutch Company, which by itself accounts for 57 percent of group 0-4's market capitalization (and the exclusion of which leaves results virtually unchanged, except naturally for the value weighted approach).
} 
In light of the magnitude of the increases in market capitalization, it is natural to wonder why shareholders had not previously banded together to try to capture the $\$ 3.2$ to $\$ 6.2$ billion by forcing insiders to move the companies to the NYSE/AMEX. We suspect that there are several possible reasons. First, it is likely that some of the 0-4 firms did not meet the listing requirements for the NYSE/AMEX (at the start of 1963, 48\% of OTC firms in group 0-4 had market capitalizations below the 25th percentile of the market capitalization of NYSE/AMEX firms). Second, insiders may have owned more than half of the shares, making it impossible for outside shareholders to force a move to the NYSE/AMEX. Third, it is probable that the $\$ 3.2$ to $\$ 6.2$ billion figure overstates the resources that could be captured by shareholders, because it is likely that at least part of this figure reflects a transfer from insiders via reduced diversion and/or increased effort. To make this effective transfer, it seems reasonable to assume that insiders would have required increased compensation. Fourth, the coordination of efforts to induce a firm to move to the NYSE/AMEX has the features of a classic public goods problem because the activist shareholder(s) cannot capture the full benefits of their efforts. ${ }^{43}$

We now discuss the internal and external validity of our results. With regards to internal validity, a few issues merit highlighting. First, some of the Period 1 unadjusted and adjusted results differ. In particular, the difference between the raw returns of the 0-4 group and its matched 4-4 group are modest and statistically indistinguishable from zero. The differences in their returns are larger and statistically significant after adjustment for the market return and three other factors. Thus, the validity of the claim that the mandatory disclosure requirements caused abnormal excess returns for the 0-4's relative to their 4-4 comparison group in Period 1 rests on the validity of the standard four-factor model of stock returns. This contrasts with the event study results, the 0-4's higher returns relative to the other OTC groups, the Period 2 results, and the operating performance results that do not rely on factor adjustment.

Second, several strands of the existing literature suggest that the large abnormal excess returns we find from improved protection of outsiders and associated reduction in expropriation by insiders are plausible. For example, Schwert [1996] documents that takeover bids (often intended to displace current management) on average are associated with about 25 percent cumulative abnormal excess returns for the target company, with larger total effects for deals that go through. Furthermore, even the type of insider trading legal under the 1933, 1934, and 1964 Acts is associated with substantial profits to insiders and corresponding losses to outsiders (see, for example Seyhun [1986]). The costs to outsiders from insider trading may have been even larger in the period before these Acts

\footnotetext{
${ }^{43}$ A fifth possibility is that these OTC firms were stuck in a "disclosers' dilemma" where firms benefit from disclosing if others disclose but non-disclosure is the best response to non-disclosure (Admati and Pfleiderer [2000]).
} 
increased the availability of reliable information about covered firms.

To the best of our knowledge, Ferrell [2004] is the only other study of the consequences of the 1964 Amendments. That paper uses a 3-factor model and finds little difference between the monthly abnormal excess returns of OTC and listed firms in the period from January 1, 1962 through January 1, 1965. However, there are a number of methodological differences that make it difficult to compare Ferrell's result with this paper's findings in a meaningful manner. Perhaps the most important difference is that Ferrell [2004] does not divide the OTC firms into those that had and had not previously registered with the SEC, nor into those above and below the size cutoffs for the 1964 Amendments. In contrast, the division of the OTC firms into the 0-4, 2-4, 0-0, and 2-2 groups is a key feature of our analysis. ${ }^{44}$

We now assess whether our results can be applied to other contexts (i.e., their external validity). Recall, the abnormal excess returns are concentrated in the 0-4 group and these firms are not a random sample of firms. Rather, the majority of these firms gave up opportunities for access to new capital through public offerings and/or the greater liquidity of the NYSE/AMEX to avoid triggering the disclosure requirements. Hence, our estimates should be considered an estimate of the "treatment on the untreated." 45

The treatment on the untreated effect could be larger or smaller than the "average treatment effect," which is the mean effect of the imposition of disclosure requirements on all firms. On the one hand, the treatment on the untreated effect might overstate the market-wide benefits of disclosure, because the firms that chose disclosure voluntarily before 1964 (e.g. by listing on the NYSE/AMEX or making a public offering and thereby subjecting themselves to the 1933 and 1934 Acts) are likely to be ones where insiders saw relatively little opportunity for diversion and therefore had little to lose if they disclosed. On the other hand, if insiders also hold a large amount of stock in their own companies, the ones who chose disclosure voluntarily might be precisely the ones whose companies' market capitalization would benefit the most from mandatory disclosure. In this case, the 0-4 firms' returns to disclosure would be lower than the average returns to disclosure.

\footnotetext{
${ }^{44}$ Ferrell [2004] reports that his sample is drawn from the Primary and Eastern tables in the OTC section of Barron's. In contrast, our sample also includes firms from the Supplemental table. In our sample, roughly seventy-five percent of the Primary and Eastern firms had registered with the SEC prior to the passage of the 1964 Amendments so we suspect that Ferrell's sample is primarily comprised of 2-2 and 2-4 firms. Recall, Table IV fails to find a significant difference between the returns of the 2-2 and 2-4 groups and their matched 4-4 groups. Other differences between the studies' examination of stock returns include: the papers divide the periods in different ways; Ferrell [2004] appears to not assign exit returns to firms that drop out of Barron's or to follow the ones that move to the NYSE/AMEX; Ferrell [2004]'s comparison group of exchange firms is not size or book-to-market matched; and our collection of the exact filing dates allows us to implement the event study tests of whether market participants valued the disclosure requirements.

${ }^{45}$ See Angrist [1998], Heckman [2001], and Rubin [1977] for discussions of the "average treatment effect," "treatment on the untreated," and related issues.
} 
It is also important to highlight that the estimates may not be applicable to settings where disclosure requirements are more stringent than those set forth in the Securities Act of 1933 and Securities and Exchange Act of 1934. For example, the results are unlikely to be directly informative about the consequences of the recent Sarbanes-Oxley Act in the United States. However, our findings are likely to be informative about the consequences of introducing mandatory disclosure regulations in the numerous developed and developing country equity markets where disclosure requirements are more lax than those specified in the U.S. legislation that is now more than 70 years old.

\section{CONCLUSION}

We analyze the last major imposition of mandatory disclosure requirements in U.S. equity markets. The 1964 Securities Acts Amendments extended several disclosure requirements to large firms traded over-the-counter (OTC) that had applied to listed firms since 1934. We find four pieces of evidence that investors valued these disclosure requirements. First, a firm-level event study reveals that OTC firms most impacted by the 1964 Amendments had abnormal excess returns of about 3.5 percent in the weeks immediately surrounding the announcement that they had begun to comply with the new requirements. Second, OTC firms that were most affected by the 1964 Amendments had higher stock returns than those that were less affected in the period between when the legislation was initially proposed and when it went into force. Third, estimates from a series of specifications indicate that the most affected OTC firms had abnormal excess returns ranging between 11.5 and 22.1 percent in the same period, relative to unaffected listed firms and after adjustment for the standard four-factor model. This implies that the 1964 Amendments created $\$ 3.2$ to $\$ 6.2$ billion (2005\$'s) of value for shareholders of the OTC firms in our sample. Fourth, the most affected OTC firms had greater income and sales growth from 1962 to 1966 than unaffected listed firms.

These results are consistent with the hypothesis that mandatory disclosure laws can cause managers to more narrowly focus on the maximization of shareholder value. However, the precise welfare consequences are unknown, because we cannot determine how much of shareholders' gains were a transfer from the insiders of these same companies. If the widely held view that diversion is inefficient and involves welfare losses is correct, then these results should cause policy makers to question the basis of recent calls to repeal U.S. federal mandatory disclosure requirements. Further,

they may provide the basis for reforms in equity markets where the forms of disclosure studied here are not mandatory. 


\section{Data Appendix}

This data appendix describes the construction of the data set on OTC companies and their stock returns from 1963-1966. It provides details on our quality assurance procedures, sample selection rules, procedures for firms that exit the sample, determination of dividends and stock splits, rules for assigning OTC firms to the different OTC groups, determination of which years (if any) the OTC firms filed with the SEC, methods to collect financial and accounting information for OTC and NYSE/AMEX firms, and construction of the 4-4 groups. Our qualitative findings are unchanged by reasonable variations on the data quality rules described here.

\section{A. Quality Assurance of Barron's Price Data}

Data entered from Barron's were hand checked and (if necessary) corrected by research assistants in the United States in any case where the bid price exceeded the ask price, a bid or ask price was not quoted in eights or the percentage difference between the bid and ask price was large.

To avoid spurious exits from Barron's and incorrect matches of firms across weeks, we used computer algorithms to compare and match firm name strings (as entered from Barron's) across weeks and flag cases where hand checking was needed due to complicated abbreviation changes. We also looked for large changes in the bid and ask prices between Barron's issues. Research assistants in the United States investigated the roughly 500 largest weekly changes in split-adjusted prices. These investigations included rechecking the Barron's entries and the stock split information, as well as verifying the match between firm names across issues of Barron's. Any documented matching errors were corrected. Otherwise, the observation was left unchanged.

\section{$\underline{\text { B. Sample Selection }}$}

\section{Firms dropped:}

The Barron's issue for the first week of 1963 lists 1,752 firms. Overall, our sample selection criteria reduces the number of OTC firms used to 1,196. The list below outlines the reasons for dropping firms and how many firms are dropped due to each criteria. The criteria were applied in the sequential order that follows.

(a) (37 firms) We drop preferred stocks and B stocks because these may be differentially affected by the law.

(b) (69 firms) Firms with no bid or ask price in the first week of 1963 are dropped.

(c) (317 firms) We drop banks and insurance companies because they are regulated by multiple agencies and the 1933, 1934, and 1964 Acts all treated one or both of these industries differently 
from other firms. Consequently, we expect that market expectations about disclosure requirements for these groups during Period 1 were likely to be different than for other firms. We classify a firm as a bank or an insurance company if it appears in Barron's in the separate sections for banks or for insurance companies, or if it appears in Barron's' general lists but is assigned an SIC code 60 (Depository Institutions), 61 (Non-depository Credit Institutions), 63 (Insurance Carriers) or 64 (Insurance Agents, Brokers, and Service). For firms that file with the SEC in any year between 1962 and 1967 we obtain SIC codes from the SEC Directory. For firms not in any of these SEC publications, we assign SIC codes based on reading firm descriptions in the 1963 Moody's Manuals. (d) (5 firms) A handful of firms had names that were too similar to allow unique matching across weeks or had information for A and B stocks that seemed mixed up across weeks making it difficult to construct a consistent time series.

(e) (5 firms) For five firms, the SESP Annual Dividend Record had incomplete or incomprehensible information about dividends or splits in one or more years. These firms are dropped.

(f) (4 firms) A few firms that were acquired in 1962, but which still had prices listed in Barrons in 1963, were dropped.

(g) (52 firms) We drop firms that appear in neither the 1962 SE्P Annual Dividend Record nor the 1963 Moody's Manuals (these Moody's Manuals generally refer to fiscal years ending in 1962). There is a risk that such firms do not publicly disclose earnings and dividends with resulting biases in returns calculated without this information.

(h) (67 firms) We drop firms that have a price less than $\$ 2$ in the first Barron's issue of 1963. Such firms have a much lower probability of still appearing in Barron's by the end of 1966. Dropping these firms from the sample makes our results less sensitive to the exact approach used for dealing with firms that exit Barron's.

Of the OTC firm drop criteria, (b) (no price in week 1 of 1963), (c) (banks and insurance companies), and (h) (initial price $<\$ 2$ ) are also relevant for NYSE/AMEX firms and are applied to these firms as well. Criterion (a) (preferred and B stocks) is not relevant for NYSE/AMEX firms, because preferred stock are not covered in CRSP and there is no reason to expect different returns for the 24 NYSE/AMEX B stocks than NYSE/AMEX A or common stocks given the lack of corporate governance reforms for NYSE/AMEX firms in the 1963-66 period.

\section{Observations dropped:}

We implement the following rules to limit the potential influence of data entry or data processing errors. Rules (a) and (b) address possible typos in a bid or ask price. Rule (c) addresses cases where Barron's or we may have entered the bid and ask price for an incorrect firm for a particular week. Rule (d) addresses extreme returns, while rule (e) addresses cases where a firm is missing 
from Barron's for a series of weeks but then re-appears in the Barron's listings.

(a) Bid price>Ask price: Observations where the bid price listed in Barron's is larger than the ask price are dropped because such cases likely result from typos by Barron's or in our data entry. Observations where Barron's list only a bid or an ask price are dropped because the average of the bid and ask (used for the calculation of returns) cannot be calculated.

(b) Bid or ask outlier: To further address likely typographical errors in the data we drop observations where the bid price is deemed to be an outlier (typo) but the ask price is not, and conversely. We classify the bid price to be an outlier if the absolute value of the one-week capital gain calculated based on the bid price exceeds fifty percent while the two-week capital gain calculated based on the bid price is below ten percent (the same classification is used for ask prices).

(c) Bid and ask outlier: To address the possibility that we or Barron's entered the wrong line of information for a particular firm in a particular week, we drop return observations where the week $t-1$ or week $t$ bid and ask prices are deemed to be a mistaken entry. Such entries are defined as cases where the resulting one-week return exceeds fifty percent in absolute value while the two-week return is below ten percent.

(d) Extreme returns: We drop observations with weekly returns above 200 percent under the presumption that most of these result from typos not caught by our above drop criteria.

(e) In cases where a firm is missing from Barron's (or is in Barron's but with missing price quotes) over a number of weeks and then reappear, we do not calculate a return for the week of the reappearance. This is done because firms may be more likely to reappear after good returns or after bad returns. Returns prior to the reappearance and for the week of the reappearance are set to missing. In cases where the firm only reappears after the following calendar year, we do not use any of the data after the reappearance because firms that are not covered for a long period of time but then reappear may be systematically different from those that do not reappear.

For comparability, we apply rules (c) and (d) to the NYSE/AMEX dataset as well. Bid/ask spreads are not available for listed firms, so we cannot apply rules (a)-(b) for those firms.

\section{$\underline{\text { C. Procedures For Firms That Exit Barron's }}$}

Appendix Table 1 summarizes our treatment of firms that exit Barron's, change names, or are involved in mergers. In cases of firms that move to the NYSE/AMEX, change names or are involved in mergers, we continue the time series of returns whenever possible. In cases of liquidations, exits from Barron's for no apparent reason, or prolonged periods of missing information in Barron's, we assign an exit return in much the same way that CRSP assigns delisting returns to firms that exit their NYSE/AMEX data set. The objective of continuing series where feasible and calculating exit 
returns otherwise is to correct for any bias in returns that may otherwise result if firms have above or below average returns in the week they exit Barron's.

The exit return is assigned to the first week where post-exit information is available and we assign zero returns in the weeks between the last Barron's price and the exit return. For comparability we use the same timing convention when assigning delisting returns in CRSP for NYSE/AMEX firms. Returns for weeks following the exit and prior to the week for which we have an exit return are set to zero.

To prevent long strings of zero returns, which could bias our estimates of factor loadings in the regressions, we do not use exit information when such information is only available for weeks more then twenty weeks past the exit. This also insures that results are not affected by censoring in the sense that information many months out may only be available for non-representative firms that exit the sample. For all weeks subsequent to the exit return, we assign a missing return. This is equivalent to assuming that the missing firms' returns for these subsequent weeks are equal to the mean return of the remaining firms in their respective OTC group (i.e., 0-4, 2-4, 0-0, and 2-2).

More specific information on our approach in six types of situations follows. The letters below correspond to groups in Appendix Table 1.

(a) Firms that exit Barron's and move to the NYSE or AMEX: We use the CRSP NYSE/AMEX files to determine which of the firms that stop being listed in Barron's Over-the-Counter section do so because they have moved to the NYSE or AMEX. The return for the week the firm first appears in CRSP is calculated using the first CRSP price and the last Barron's price, and information on dividends and stock splits from SESP Annual Dividend Record. In over 94 percent of the cases the firm appears in CRSP in the first week after exiting from Barron's. In a few cases there is a one, two, or three week gap between the Barron's exit and the first appearance in CRSP. The return for this week is set to zero. In a few other cases, Barron's lists prices for a few weeks following the appearance in CRSP. We use the CRSP prices to calculate returns for these weeks. In weeks following the first week of the CRSP appearance, we calculate weekly returns based on CRSP's information on prices, dividends, and stock splits. For simplicity, we calculate weekly returns in CRSP based on the daily returns provided (this allows for an intra-week return on any dividends paid but we confirmed that any resulting bias from this is minuscule by alternatively calculating returns using the prices, dividends, and splits directly).

(b) Firms that change names: Name changes are identified using the Moody's Manuals, NSS, and Directory of Obsolete Securities. When Barron's continues coverage of the firm under the new name we are able continue the time series of returns for the firm. When the new firm name does not appear in Barron's, we assign, when possible, an exit return based on the first post-exit price 
found in the NSS and dividend and stock split information from SESP Annual Dividend Record. The exit return is assigned to the week of the NSS price. Weeks between the exit from Barron's and the NSS price are assigned a return of zero.

(c) Firms involved in mergers: Mergers and merger terms are identified using the Moody's Manuals, NSS, and Directory of Obsolete Securities. When the acquiring company is in Barron's or on the NYSE/AMEX we are able to continue the time series of returns for the firm. Otherwise we assign an exit return whenever possible, based on the first post-exit price found in the NSS and dividend and stock split information from SESP Annual Dividend Record. The exit return is assigned to the week of the NSS price. Weeks between the exit from Barron's and the NSS price are assigned a return of zero. When merger terms are unavailable, we set the return for the merger week to missing. In cases of acquisitions for cash, we assign an exit return and do not continue the time series.

(d) Firms that are liquidated: Liquidations are identified using the Moody's Manuals, Directory of Obsolete Securities, and SEP Annual Dividend Record. When possible, we assign exit return based on either information about liquidating dividends or the first post-exit price found in the NSS and dividend and stock split information from SESP Annual Dividend Record. The exit return is assigned to the week of the liquidating dividend or NSS price and weeks in between the exit from Barron's and the NSS price are assigned a return of zero.

(e), (f) Firms that exit Barron's for no apparent reason or for which we discontinue the return series due to long periods of missing information in Barron's: Appendix Table 1 splits these firms into those that exit with a last price above two dollars and those that exit with a last price of two dollars or less. The latter category is larger, suggesting that Barron's tends to drop coverage of firms with very low prices. When possible, we use the $N S S$ as described in (d) to assign an exit return.

Appendix Table 1 summarizes the causes of attrition from Barron's. Within each of these categories, it also provides counts of the securities for which the time series could be continued. We succeeded in assigning an exit return for 78 percent of the securities where it was impossible to continue the time series. The largest single source of attrition from the Barron's sample is movement to NYSE or AMEX. Over the course of the four years, 23 percent of the OTC sample firms move to the NYSE or the AMEX. The frequency of movements to exchanges is especially high in 1963 and 1964, slows somewhat in 1965, and slows even more in 1966. This is consistent with the notion that, as mandatory disclosure requirements became more likely, the value of staying unlisted declined.

To evaluate the importance of these efforts to follow the stock prices of firms that exit Barron's, 
we repeated our estimations without assigning exit returns or continuing series using information about moves to NYSE/AMEX, name changes, and mergers. The $\alpha_{0-4}^{P d} 1$ estimate from the column (5) specification of Table IV is 0.135 with a standard error of 0.045 if exit returns are not assigned, compared to the estimate of 0.097 with a standard error of 0.046 in Table IV from the primary data file that includes exit returns. It is evident that the paper's estimates of the effect of the 1964 Amendments would be overstated if we had not collected exit returns.

\section{$\underline{\text { D. Dividend Data }}$}

Our primary source for dividends and stock splits was SESP Annual Dividend Record. This publication aims to be a "record of dividend payments on virtually every American and Canadian preferred and common stock." The average number of firms covered in this publication during the 1961-68 period was 10,000. There were roughly 2,000 firms on the American and New York Stock Exchanges in these years, so approximately eighty percent of the entries were for OTC (and Canadian) firms. Approximately 85 percent of our 1,196 OTC firms were in the 1962 S\&P book. We entered the amounts and dates of every cash, property, and liquidating dividend and stock split for each of the OTC firms in the sample. When necessary, we used the NSS and the Directory of Obsolete Securities to verify dividends.

As mentioned above, we dropped 52 firms that appeared in Barron's, but failed to appear in either the 1962 S\&P Annual Dividend Record or the 1963 Moody's Manuals. There is a risk that such firms do not publicly disclose earnings and dividends. For the vast majority of remaining firms not in the $1962 \mathrm{~S} \& \mathrm{P}$ book, we were able to use the Moody's Manuals to verify that no dividends or splits had taken place in 1962 or confirm that the firms were included in the $1963 \mathrm{~S} \& \mathrm{P}$ book that covers the dividends for the first year of our analysis.

$\underline{\text { E. Assignment to OTC Groups }}$

We assigned each OTC firm to one of four OTC groups based on information at the start of 1963. The 0-4 group is comprised of firms that were not filing annual reports with the SEC and exceeded the size and asset floors set forth in the 1964 Amendments. We assume that firms with measured assets exceeding $\$ 1$ million and more than 500 shareholders and firms with measured assets exceeding $\$ 5$ million but missing shareholder data qualify as exceeding the size and assets floors. The 2-4 group includes firms that were filing periodic reports with the SEC and exceeded the size and asset floors described in the previous sentence. The 2-2 group is comprised of firms that fail to exceed the size and asset floor rules and were filing periodic reports. The 0-0 firms also fail to exceed the size and asset floor rules and were not filing periodic reports with the SEC. 
The asset and stockholder characteristics as of the start of 1963 are obtained from the 1962 and 1963 Moody's Manuals. We ascertained the identity of firms that filed with the SEC from the 1963 edition of the SEC Directory. This publication lists the firms that file with the SEC in the year ending in July 1963. Because we are interested in filing status as of the start of 1963, we classify firms that appear in the 1963 SEC Directory but (a) went to NYSE/AMEX in the first half of 1963 and (b) did not file with the SEC according to the 1962 SEC Directory as initial non-filers (i.e. as 0-4 or 0-0 firms).

$\underline{\text { F. Determination of Compliance with Mandatory Disclosure Requirements }}$

An essential component of the analysis is the accurate identification of the firms that disclose financial information through official SEC channels. The SEC Directory reports the identities of each company that complies with mandated disclosure requirements. Each company's filing status was collected annually for our sample of OTC firms. The U.S. SEC News Digest lists the exact date that the SEC considered the complying firms in our sample to have fulfilled the registration requirement in the case of the 0-4 firms and initiated the filing of proxy and insider trading reports in the case of the 2-4 firms. We use these exact dates to implement a firm-level event study analysis of the consequences of the initial compliance with these disclosure requirements.

G. Accounting and Industry Data

We gathered accounting information for firms in our OTC sample from the annual Moody's Manuals. The industry, or SIC code, of the OTC firms was determined from the Moody's Manuals and the SEC Directory. The COMPUSTAT electronic files are the primary source for accounting and industry data for NYSE/AMEX firms. For NYSE/AMEX firms not covered in COMPUSTAT, we collected this information from the Moody's Manuals supplemented with book equity information available from Kenneth French's web page and used in Davis, Fama and French [2000].

\section{H. Construction of 4-4 Groups}

We construct separate 4-4 comparison groups for each of the four OTC groups. These 4-4 groups are constructed so that the distributions of the underlying firms' market capitalizations and book value of equity to market value of equity are similar to these distributions in the corresponding OTC group. The 4-4 groups that correspond to the 0-4 and 2-4 groups are constructed in the following four steps:

1. The NYSE/AMEX firms present in CRSP at the beginning of 1963 are divided into five market capitalization quintiles and five quintiles of book value of equity to market capitalization, 
thus creating 25 cells of firms. To be comparable to our approach to constructing the OTC groups, these 25 cells are never refreshed to include new entrants to CRSP or changes in existing firms' market capitalization or book value of equity to market capitalization. Consequently, the numbers of firms in each will decline over time as firms go bankrupt or disappear from CRSP for other reasons.

2. We calculate the weekly unweighted average returns of each of the 25 cells. We then determine which of the 25 cells of the NYSE/AMEX firms each OTC firm would belong to in the first week of 1963 if it were trading on the NYSE or AMEX. The firm is then matched to that cell throughout the analysis.

3. The weekly portfolio returns of each OTC group's matched 4-4 group in a given week are calculated as the weighted average of the 25 NYSE/AMEX cell index returns. Each cell's weight is equal to the fraction of the OTC group's firms with a non-missing return in the relevant week that are matched to that cell.

If the 0-4 and 2-4 groups of OTC firms had been traded on the NYSE/AMEX, their mean (median) market capitalization quintiles would have been 1.95 (2) and 2.14 (2), respectively. Their median (mean) book to market quintiles would have been 3.14 (3) and 2.69 (3), respectively. Quintile 1 is comprised of the firms with the smallest values of market capitalization and book to market, respectively. The market capitalization is missing for fewer than ten of the $0-4$ and 2-4 firms. We assume that these firms' market capitalization equal their assets multiplied by the median market capitalization to asset ratio of the firms in their group.

We use the return on the smallest NYSE/AMEX size quintile portfolio as a size-matched 4-4 group for the 0-0 and 2-2 groups. For these groups, we are unable to also match on book-to-market equity, because market capitalization data is unavailable for most OTC firms in these groups. We use the smallest size quintile because, as Table II demonstrated they are much smaller than the 0-4 and 2-4 firms in terms of assets and sales. 


\section{REFERENCES}

Admati, Anat R. and Paul C. Pfleiderer, "Forcing Firms to Talk: Financial Disclosure Regulation and Externalities," Review of Financial Studies, XIII (2000), 479-519.

Angrist, Joshua A., "Estimating the Labor Market Impact of Voluntary Military Service Using Social Security Data on Military Applicants," Econometrica, LXVI (1998), 249-288.

Augenbraun, Barry S., "Courts in Two States Reaffirm the Requirement of Privity for Accountants' Liability," The CPA Journal, LXIII (1993), 44-46.

Benston, George J., "Required Disclosure and the Stock Market: An Evaluation of the Securities Exchange Act of 1934," American Economic Review, LXIII (1973), 132-155.

Bushee, Brian J. and Christian Leuz, "Economic Consequences of SEC Disclosure Regulation: Evidence from the OTC Bulletin Board," Journal of Accounting and Economics, XXXIX (2005), 233-264.

Carhart, Mark M., "On Persistence in Mutual Fund Performance," Journal of Finance, LII (1997), $57-82$.

Castro, Rui, Gian Luca Clementi, and Glenn M. MacDonald, "Investor Protection, Optimal Incentives, and Economic Growth," Quarterly Journal of Economics, CXIX (2004), 1131-1175.

Chow, Chee W., "The Impacts of Accounting Regulation on Bondholder and Shareholder Wealth: The Case of the Securities Acts," The Accounting Review, LVIII (1983), 485-520.

Coase, Ronald, "The Problem of Social Cost," Journal of Law and Economics, III (1960), 1-44.

Coffee, John C., "Market Failure and the Economic Case for a Mandatory Disclosure System," Virginia Law Review, LXX (1984), 717-753.

Davis, James L., Eugene F. Fama, and Kenneth R. French, "Characteristics, Covariances, and Average Returns: 1929 to 1997," Journal of Finance, LV (2000), 389-406.

Easterbrook, Frank H. and Daniel R. Fischel, "Mandatory Disclosure and the Protection of Investors," Virginia Law Review, LXX (1984), 669-715.

Fama, Eugene F. and Kenneth R. French, "The Cross-Section of Expected Stock Returns," Journal of Finance, XLVII (1992), 427-465. 
Fama, Eugene F. and Kenneth R. French, "Common Risk Factors in the Returns on Stocks and Bonds," Journal of Financial Economics, XXXIII (1993), 3-56.

Ferrell, Allen, "Mandated Disclosure and Stock Returns: Evidence from the Over-the-Counter Market," Working Paper, Harvard Law School, 2004.

Friend, Irwin and Edward S. Herman, "The SEC Through a Glass Darkly," Journal of Business, XXXVII (1964), 382-405.

Glaeser, Edward and Andrei Shleifer, "The Rise of the Regulatory State," Journal of Economic Literature, XLI (2003), 401-425.

Healy, Paul M. and Krishna G. Palepu, "Information Asymmetry, Corporate Disclosure, and the Capital Markets: A Review of the Empirical Disclosure Literature," Journal of Accounting and Economics, XXXI (2001), 405-440.

Heckman, James J., "Sample Selection Bias as a Specification Error," Econometrica, XLVII (1979), $153-162$.

Heckman, James J., "Micro Data, Heterogeneity, and the Evaluation of Public Policy: Nobel Lecture," Journal of Political Economy, CIX (2001), 673-748.

Jarrell, Gregg A., "The Economic Effects of Federal Regulation of the Market for New Security Issues," Journal of Law and Economics, XXIV (1981), 613-675.

La Porta, Rafael, Florencio Lopez de Silanes, and Andrei Shleifer, "Corporate Ownership Around the World," Journal of Finance, LIV (1999), 471-517.

La Porta, Rafael, Florencio Lopez de Silanes, Andrei Shleifer, and Robert W. Vishny, "Legal Determinants of External Finance," Journal of Finance, CII (1997), 1131-1150.

La Porta, Rafael, Florencio Lopez de Silanes, Andrei Shleifer, and Robert W. Vishny, "Investor Protection and Corporate Valuation," Journal of Finance, LVII (2002), 1147-1170.

Loss, Louis, Fundamentals of Securities Regulation, (Boston: Little, Brown and Company, 1983).

Loughran, Tim and Jay R. Ritter, "The New Issues Puzzle," Journal of Finance, L (1995), 23-51.

Madhavan, Ananth, "Market Microstructure: A Survey," Journal of Financial Markets, III (2000), $205-258$. 
Mahoney, Paul G., "Mandatory Disclosure as a Solution to Agency Problems," University of Chicago Law Review, LXII (1995), 1047-1112.

Mahoney, Paul G., "The Exchange as Regulator," Virginia Law Review, LXXXIII (1997), 14531500.

Mahoney, Paul G., "The Origins of the Blue-Sky Laws: A Test of Competing Hypotheses," Journal of Law and Economics, XLVI (2003), 229-251.

Palmiter, Alan R., "Toward Disclosure Choice in Securities Offerings," Columbia Business Law Review, (1999), 1-135.

Rajan, Raghuram G. and Luigi Zingales, "Financial Dependence and Growth," American Economic Review, LXXXVIII (1998), 559-586.

Robbins, Sidney and Walter Werner, "Professor Stigler Revisited," Journal of Business, XXXVII (1964), 406-413.

Romano, Roberta, "Empowering Investors: A Market Approach to Securities Regulation," Yale Law Journal, CVII (1998), 2359-2430.

Rubin, Donald, "Assignment to Treatment Group on the Basis of a Covariate," Journal of Educational Statistics, I (1977), 1-26.

Schwert, G. William, "Markup Pricing in Mergers and Acquisitions," Journal of Financial Economics, XLI (1996), 153-192.

Seligman, Joel, The Transformation of Wall Street, (Boston: Northeastern University Press, 1995).

Seyhun, H. Nejat, "Insiders' Profits, Costs of Trading, and Market Efficiency," Journal of Financial Economics, XVI (1986), 189-212.

Shleifer, Andrei and Daniel Wolfenzon, "Investor Protection and Equity Markets," Journal of Financial Economics, LXVI (2002), 3-27.

Simon, Carol J., "The Effect of the 1933 Securities Act on Investor Information and the Performance of New Issues," American Economic Review, LXXIX (1989), 295-318.

Stigler, George, "Public Regulation of the Securities Markets," Journal of Business, XXXVII (1964), 117-142. 
United States Securities and Exchange Commission, Report of Special Study of Securities Markets of the Securities and Exchange Commission, (Washington: United States Securities and Exchange Commission, 1963).

Verrecchia, Robert E., "Essays on Disclosure," Journal of Accounting and Economics, XXXI (2001), 97-180. 


\section{TABLE I}

Key Dates Associated with the Securities Acts Amendments of 1964 and with Research Design

1. Beginning of Period 1 (and Period 1a), January 1, 1963: Sample of OTC firms' stock returns begins. We assume full impact of 1964 Securities Acts Amendments on stock returns occurs in this period.

2. April 3, 1963: The SEC releases the first part of the Special Study. It recommends imposing exchange disclosure rules on OTC securities.

3. July 9, 1963: House subcommittee unanimously approves bill extending disclosure requirements to all OTC firms.

4. July 30, 1963: Senate passes a bill extending disclosure rules to OTC firms with at least $\$ 1$ million in assets and 500 shareholders.

5. February, 1964: President Johnson endorses legislation and lobbies Congress to further its prospects for passage.

6. March 19, 1964: House subcommittee passes bill and it becomes evident Congress as a whole will pass it.

7. August 5-6, 1964: House and Senate passed the bill.

8. End of Period 1a, August 24, 1964; President Johnson signs 1964 Securities Acts Amendments into law on August 20, 1964.

9. Beginning of Period 1b, August 24, 1964: OTC firms with at least $\$ 1$ million of assets and 750 shareholders required to initially file with SEC during this period.

10. April 30, 1965 is the deadline for covered firms with fiscal year ends between July 1, 1964 and December 31, 1964 to initially file. Covered firms with fiscal year ends between January 1, 1965 and June 30, 1965 required to initially file 120 days after fiscal year end.

11. October 31, 1965: Last deadline for filing registration statement with SEC for newly covered firms.

12. End of Period 1 (and Period 1b), November 15, 1965: Period 1 ends two weeks after October 31 deadline to allow for gradual dissemination of news about which firms filed with the SEC.

13. Beginning of Period 2, November 15, 1965: Virtually no new information about the law or which firms would comply with its requirements was revealed in this period. This period is used to assess the validity of the Period 1 findings.

14. End of Period 2, December 31, 1966: Sample of OTC firms' stock returns ends. 
TABLE II

Firm Characteristics by Mandatory Disclosure Groups, 1962

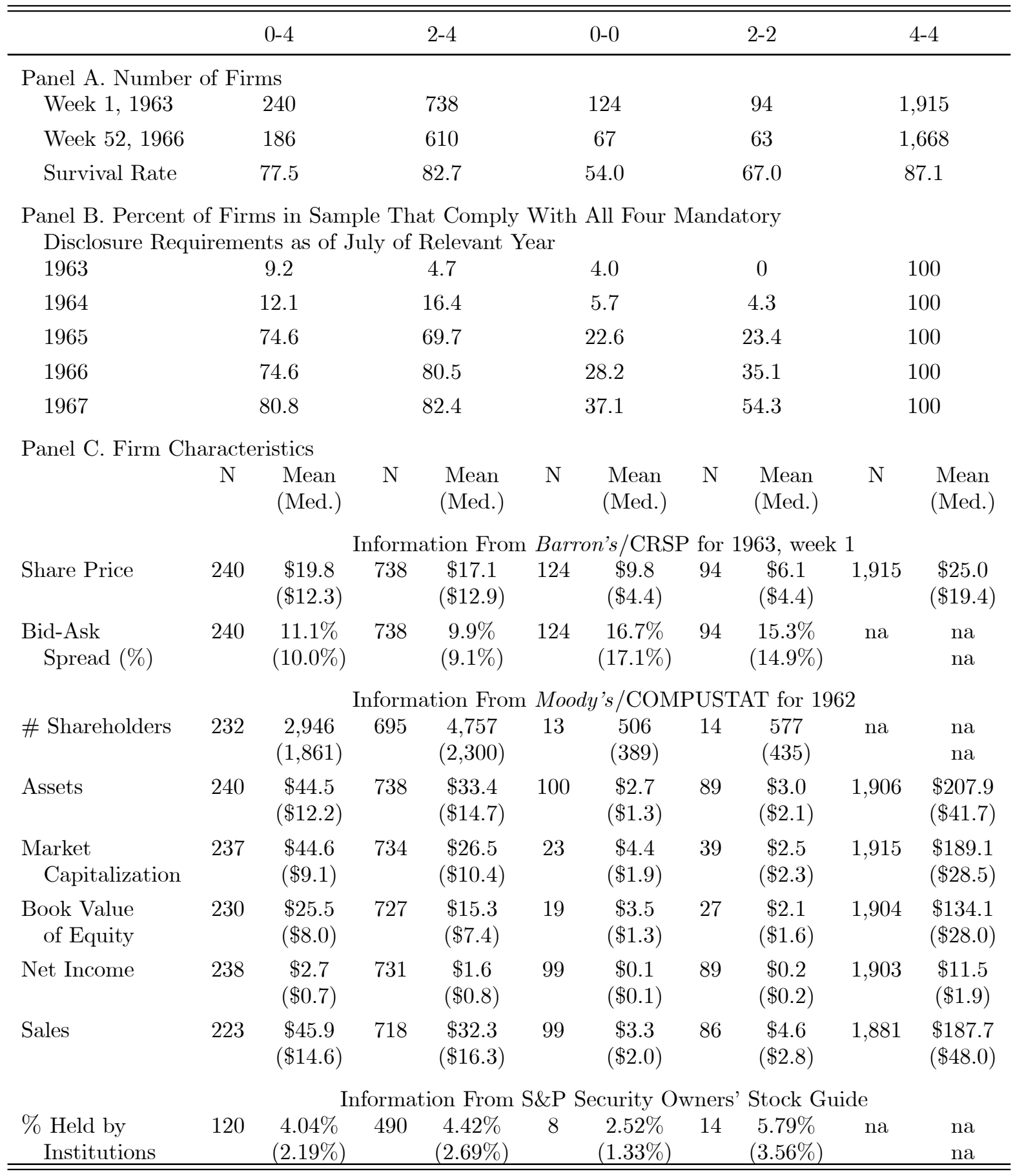

Note: All firms tabulated in the OTC and NYSE/AMEX groups are present in their respective samples as of the first week of 1963. NYSE/AMEX firms tabulated exclude firms that enter from the Barron's sample during the 63-66 period. All dollar figures are in millions, except per share data. Means and medians are calculated using available observations. 
TABLE III

Firm Level Analysis of SEC Registration

\begin{tabular}{|c|c|c|c|c|c|c|}
\hline & \multicolumn{3}{|c|}{$0-4-4-4$} & \multicolumn{3}{|c|}{$2-4-4-4$} \\
\hline & $(1)$ & $(2)$ & $(3)$ & $(4)$ & $(5)$ & $(6)$ \\
\hline $\begin{array}{l}\text { 1(10-Week Period From } \\
\text { Filing To Registration) }\end{array}$ & $\begin{array}{c}0.358 \\
(0.177)\end{array}$ & $\begin{array}{c}0.350 \\
(0.173)\end{array}$ & $\begin{array}{c}0.344 \\
(0.162)\end{array}$ & $\begin{array}{c}0.369 \\
(0.103)\end{array}$ & $\begin{array}{c}0.350 \\
(0.097)\end{array}$ & $\begin{array}{c}0.312 \\
(0.092)\end{array}$ \\
\hline Constant & $\begin{array}{c}0.002 \\
(0.099)\end{array}$ & $\begin{array}{c}0.082 \\
(0.082)\end{array}$ & $\begin{array}{c}0.060 \\
(0.069)\end{array}$ & $\begin{array}{l}-0.151 \\
(0.090)\end{array}$ & $\begin{array}{l}-0.040 \\
(0.071)\end{array}$ & $\begin{array}{l}-0.013 \\
(0.051)\end{array}$ \\
\hline R-Squared & 0.001 & 0.007 & 0.005 & 0.001 & 0.004 & 0.003 \\
\hline Factor Model & None & 4 Factors & 4 Factors & None & 4 Factors & 4 Factors \\
\hline Firms & 145 & 145 & 215 & 417 & 417 & 693 \\
\hline Observations (Firm-Weeks) & 8,845 & 8,845 & 12,824 & 25,857 & 25,857 & 42,277 \\
\hline Full Sample & No & No & Yes & No & No & Yes \\
\hline
\end{tabular}

Note: The sample in columns 1 and 4 includes all firms that belong to either group 0-4 or group 2-4 and for which returns during the period are available. Columns 2, 3, 5, and 6 limit the sample to firms that register with the SEC before the end of period 1. The indicator variable 1(Period Between Filing and Registration) equals 1 between the 8 weeks before registration and the 1 week after registration (both inclusive). Columns $1,2,4$, and 5 include a constant terms as the only other explanatory variable. Columns 3 and 6 also includes the market, size, book-to-market, and momentum factors. Clustered standard errors, allowing for correlation across firms within weeks, are in parentheses. 


\section{TABLE IV}

Average Abnormal Excess Return;

Period 1, January 1963 - November 15, 1965

\begin{tabular}{|c|c|c|c|c|c|c|c|c|}
\hline & (1) & $(2)$ & $(3)$ & (4) & $(5)$ & (6) & $(7)$ & (8) \\
\hline & \multicolumn{2}{|c|}{$0-4$} & \multicolumn{6}{|c|}{$(0-4)-(4-4)$} \\
\hline$\alpha_{0-4}^{P d 1}(\%)$ & $\begin{array}{c}0.378 \\
(0.077)\end{array}$ & $\begin{array}{c}0.187 \\
(0.050)\end{array}$ & $\begin{array}{c}0.053 \\
(0.048)\end{array}$ & $\begin{array}{c}0.078 \\
(0.048)\end{array}$ & $\begin{array}{c}0.097 \\
(0.046)\end{array}$ & $\begin{array}{c}0.129 \\
(0.048)\end{array}$ & $\begin{array}{c}0.083 \\
(0.048)\end{array}$ & $\begin{array}{c}0.149 \\
(0.047)\end{array}$ \\
\hline \multirow[t]{2}{*}{ R-squared } & - & 0.639 & - & 0.028 & 0.191 & 0.195 & 0.213 & 0.160 \\
\hline & \multicolumn{2}{|c|}{$2-4$} & \multicolumn{6}{|c|}{$(2-4)-(4-4)$} \\
\hline$\alpha_{2-4}^{P d 1}(\%)$ & $\begin{array}{c}0.296 \\
(0.080)\end{array}$ & $\begin{array}{c}0.095 \\
(0.049)\end{array}$ & $\begin{array}{l}-0.010 \\
(0.045)\end{array}$ & $\begin{array}{c}0.013 \\
(0.043)\end{array}$ & $\begin{array}{c}0.024 \\
(0.040)\end{array}$ & $\begin{array}{c}0.057 \\
(0.043)\end{array}$ & $\begin{array}{c}0.035 \\
(0.048)\end{array}$ & $\begin{array}{c}0.056 \\
(0.039)\end{array}$ \\
\hline \multirow[t]{2}{*}{ R-squared } & - & 0.667 & - & 0.026 & 0.133 & 0.120 & 0.166 & 0.079 \\
\hline & \multicolumn{2}{|c|}{$0-0$} & \multicolumn{6}{|c|}{$(0-0)-(4-4)$} \\
\hline$\alpha_{0-0}^{P d 1}(\%)$ & $\begin{array}{c}0.257 \\
(0.110)\end{array}$ & $\begin{array}{c}0.063 \\
(0.092)\end{array}$ & $\begin{array}{l}-0.095 \\
(0.096)\end{array}$ & $\begin{array}{l}-0.075 \\
(0.095)\end{array}$ & $\begin{array}{l}-0.095 \\
(0.098)\end{array}$ & $\begin{array}{c}-0.109 \\
(0.117)\end{array}$ & $\begin{array}{l}-0.116 \\
(0.135)\end{array}$ & $\begin{array}{c}0.000 \\
(0.105)\end{array}$ \\
\hline \multirow[t]{2}{*}{ R-squared } & - & 0.326 & - & 0.004 & 0.056 & 0.040 & 0.056 & 0.059 \\
\hline & \multicolumn{2}{|c|}{$2-2$} & \multicolumn{6}{|c|}{$(2-2)-(4-4)$} \\
\hline$\alpha_{2-2}^{P d 1}(\%)$ & $\begin{array}{c}0.214 \\
(0.130)\end{array}$ & $\begin{array}{c}0.033 \\
(0.115)\end{array}$ & $\begin{array}{l}-0.138 \\
(0.106)\end{array}$ & $\begin{array}{l}-0.131 \\
(0.107)\end{array}$ & $\begin{array}{l}-0.125 \\
(0.114)\end{array}$ & $\begin{array}{c}-0.071 \\
(0.116)\end{array}$ & $\begin{array}{l}-0.110 \\
(0.127)\end{array}$ & $\begin{array}{c}-0.021 \\
(0.112)\end{array}$ \\
\hline R-squared & - & 0.296 & - & 0.000 & 0.001 & 0.000 & 0.038 & 0.024 \\
\hline \multicolumn{9}{|c|}{ Test of equal $\alpha, \mathrm{p}$-value } \\
\hline$\alpha_{0-4}^{P d 1}=\alpha_{2-4}^{P d 1}$ & 0.014 & 0.015 & 0.064 & 0.054 & 0.053 & 0.046 & 0.284 & 0.020 \\
\hline$\alpha_{0-4}^{P d 1}=\alpha_{0-0}^{P d 1}$ & 0.149 & 0.167 & 0.100 & 0.087 & 0.049 & 0.051 & 0.146 & 0.160 \\
\hline$\alpha_{0-4}^{P d 1}=\alpha_{2-2}^{P d 1}$ & 0.097 & 0.128 & 0.054 & 0.032 & 0.030 & 0.062 & 0.107 & 0.100 \\
\hline Factor Model & None & $4 \mathrm{~F}$ & None & CAPM & $4 \mathrm{~F}$ & $4 \mathrm{~F}$ & $4 \mathrm{~F}$ & $4 \mathrm{~F}$ \\
\hline Buy and Hold & No & No & No & No & No & Yes & Yes & No \\
\hline Value Weighted & No & No & No & No & No & No & Yes & No \\
\hline Industry Matched & No & No & No & No & No & No & No & Yes \\
\hline
\end{tabular}

Note: The entries in columns 1 and 2 are the parameter estimates and heteroscedasticity-consistent standard errors (in parentheses) on the constant from the estimation of versions of equation (2). Columns 3-8 are based on estimates of equation (3). Bold-face panel headings denote groups and the specification details are at the bottom of the table. The sample size is 148 weeks, but it is based on 149 calendar weeks. See footnote 31 for details. "CAPM" indicates that the regression controls for the return on the market. " $4 \mathrm{~F}$ " indicates controls for the market, size, book-to-market and momentum factors. Details on these factors, as well as our methodology for "buy and hold" returns, value weighting, and adjusting for industry returns are provided in the text. 


\section{TABLE V}

Average Abnormal Excess Return

January 1963 - August 24, 1964 (Period 1a) and

August 24, 1964 - November 15, 1965 (Period 1b)

\begin{tabular}{|c|c|c|c|c|c|c|c|c|}
\hline & (1) & $(2)$ & (3) & $(4)$ & $(5)$ & (6) & $(7)$ & $(8)$ \\
\hline & \multicolumn{2}{|c|}{$0-4$} & \multicolumn{6}{|c|}{$(0-4)-(4-4)$} \\
\hline$\alpha_{0-4}^{P d 1 a}(\%)$ & $\begin{array}{c}0.299 \\
(0.095)\end{array}$ & $\begin{array}{c}0.223 \\
(0.076)\end{array}$ & $\begin{array}{c}0.066 \\
(0.064)\end{array}$ & $\begin{array}{c}0.100 \\
(0.065)\end{array}$ & $\begin{array}{c}0.115 \\
(0.068)\end{array}$ & $\begin{array}{c}0.141 \\
(0.070)\end{array}$ & $\begin{array}{c}0.122 \\
(0.074)\end{array}$ & $\begin{array}{c}0.165 \\
(0.068)\end{array}$ \\
\hline \multirow[t]{2}{*}{ R-squared } & - & 0.521 & - & 0.035 & 0.132 & 0.153 & 0.186 & 0.172 \\
\hline & \multicolumn{2}{|c|}{$0-4$} & \multicolumn{6}{|c|}{$(0-4)-(4-4)$} \\
\hline$\alpha_{0-4}^{P d}{ }^{P b}(\%)$ & $\begin{array}{c}0.483 \\
(0.127)\end{array}$ & $\begin{array}{c}0.206 \\
(0.067)\end{array}$ & $\begin{array}{c}0.036 \\
(0.072)\end{array}$ & $\begin{array}{c}0.053 \\
(0.071)\end{array}$ & $\begin{array}{c}0.106 \\
(0.065)\end{array}$ & $\begin{array}{c}0.133 \\
(0.067)\end{array}$ & $\begin{array}{c}0.039 \\
(0.057)\end{array}$ & $\begin{array}{c}0.174 \\
(0.069)\end{array}$ \\
\hline \multirow[t]{2}{*}{ R-squared } & - & 0.778 & - & 0.021 & 0.328 & 0.281 & 0.252 & 0.194 \\
\hline & \multicolumn{2}{|c|}{$2-4$} & \multicolumn{6}{|c|}{$(2-4)-(4-4)$} \\
\hline$\alpha_{2-4}^{P d 1 a}(\%)$ & $\begin{array}{c}0.230 \\
(0.102)\end{array}$ & $\begin{array}{c}0.129 \\
(0.081)\end{array}$ & $\begin{array}{c}0.030 \\
(0.061)\end{array}$ & $\begin{array}{c}0.052 \\
(0.059)\end{array}$ & $\begin{array}{c}0.052 \\
(0.066)\end{array}$ & $\begin{array}{c}0.086 \\
(0.067)\end{array}$ & $\begin{array}{c}0.141 \\
(0.070)\end{array}$ & $\begin{array}{c}0.088 \\
(0.065)\end{array}$ \\
\hline \multirow[t]{2}{*}{ R-squared } & - & 0.583 & - & 0.016 & 0.097 & 0.089 & 0.140 & 0.127 \\
\hline & \multicolumn{2}{|c|}{$2-4$} & \multicolumn{6}{|c|}{$(2-4)-(4-4)$} \\
\hline$\alpha_{2-4}^{P d}{ }^{P d}(\%)$ & $\begin{array}{c}0.381 \\
(0.128)\end{array}$ & $\begin{array}{c}0.112 \\
(0.058)\end{array}$ & $\begin{array}{c}-0.062 \\
(0.065)\end{array}$ & $\begin{array}{l}-0.039 \\
(0.063)\end{array}$ & $\begin{array}{c}0.026 \\
(0.053)\end{array}$ & $\begin{array}{c}0.058 \\
(0.060)\end{array}$ & $\begin{array}{l}-0.068 \\
(0.064)\end{array}$ & $\begin{array}{c}0.061 \\
(0.049)\end{array}$ \\
\hline R-squared & - & 0.787 & - & 0.046 & 0.265 & 0.229 & 0.282 & 0.112 \\
\hline \multicolumn{9}{|c|}{ Test of equal $\alpha, \mathrm{p}$-value } \\
\hline$\alpha_{0-4}^{P d 1 a}=\alpha_{2-4}^{P d 1 a}$ & 0.133 & 0.070 & 0.426 & 0.278 & 0.214 & 0.258 & 0.773 & 0.149 \\
\hline$\alpha_{0-4}^{P d 1 b}=\alpha_{2-4}^{P d 1 b}$ & 0.045 & 0.091 & 0.057 & 0.079 & 0.153 & 0.173 & 0.053 & 0.060 \\
\hline Factor Model & None & $4 \mathrm{~F}$ & None & CAPM & $4 \mathrm{~F}$ & $4 \mathrm{~F}$ & $4 \mathrm{~F}$ & $4 \mathrm{~F}$ \\
\hline Buy and Hold & No & No & No & No & No & Yes & Yes & No \\
\hline Value Weighted & No & No & No & No & No & No & Yes & No \\
\hline Industry Matched & No & No & No & No & No & No & No & Yes \\
\hline
\end{tabular}

Note: The entries in columns 1 and 2 are the parameter estimates and heteroscedasticity-consistent standard errors (in parentheses) on the constant from the estimation of versions of equation (2). Columns 3-8 are based on estimates of equation (3). Bold-face panel headings denote groups and the specification details are at the bottom of the table. The sample size is 85 weeks for Period 1a and 64 weeks for Period 1b. "CAPM" indicates that the regression controls for the return on the market. " $4 \mathrm{~F}$ " indicates controls for the market, size, book-to-market, and momentum factors. Details on these factors, as well as our methodology for "buy and hold" returns, value weighting, and adjusting for industry returns are provided in the text. 


\section{TABLE VI}

Average Abnormal Excess Return

Period 2, November 15, 1965 through end of 1966

\begin{tabular}{|c|c|c|c|c|c|c|c|c|}
\hline & (1) & $(2)$ & (3) & (4) & $(5)$ & (6) & $(7)$ & (8) \\
\hline & \multicolumn{2}{|c|}{$0-4$} & \multicolumn{6}{|c|}{$(0-4)-(4-4)$} \\
\hline$\alpha_{0-4}^{P d 2}(\%)$ & $\begin{array}{c}-0.031 \\
(0.231)\end{array}$ & $\begin{array}{c}0.076 \\
(0.083)\end{array}$ & $\begin{array}{l}-0.097 \\
(0.111)\end{array}$ & $\begin{array}{l}-0.149 \\
(0.090)\end{array}$ & $\begin{array}{c}-0.022 \\
(0.077)\end{array}$ & $\begin{array}{l}-0.020 \\
(0.115)\end{array}$ & $\begin{array}{l}-0.105 \\
(0.093)\end{array}$ & $\begin{array}{c}0.018 \\
(0.095)\end{array}$ \\
\hline \multirow[t]{2}{*}{ R-Squared } & - & 0.912 & - & 0.373 & 0.669 & 0.586 & 0.666 & 0.395 \\
\hline & \multicolumn{2}{|c|}{$2-4$} & \multicolumn{6}{|c|}{$(2-4)-(4-4)$} \\
\hline$\alpha_{2-4}^{P d 2}(\%)$ & $\begin{array}{l}-0.014 \\
(0.235)\end{array}$ & $\begin{array}{c}0.060 \\
(0.073)\end{array}$ & $\begin{array}{l}-0.075 \\
(0.106)\end{array}$ & $\begin{array}{l}-0.127 \\
(0.082)\end{array}$ & $\begin{array}{l}-0.035 \\
(0.074)\end{array}$ & $\begin{array}{c}0.007 \\
(0.092)\end{array}$ & $\begin{array}{c}-0.034 \\
(0.088)\end{array}$ & $\begin{array}{l}-0.022 \\
(0.069)\end{array}$ \\
\hline \multirow[t]{2}{*}{ R-Squared } & - & 0.938 & - & 0.409 & 0.627 & 0.602 & 0.765 & 0.416 \\
\hline & \multicolumn{2}{|c|}{$0-0$} & \multicolumn{6}{|c|}{$(0-0)-(4-4)$} \\
\hline$\alpha_{0-0}^{P d 2}(\%)$ & $\begin{array}{c}0.276 \\
(0.318)\end{array}$ & $\begin{array}{c}0.303 \\
(0.212)\end{array}$ & $\begin{array}{c}0.150 \\
(0.206)\end{array}$ & $\begin{array}{c}0.111 \\
(0.213)\end{array}$ & $\begin{array}{c}0.172 \\
(0.235)\end{array}$ & $\begin{array}{c}0.169 \\
(0.261)\end{array}$ & $\begin{array}{c}0.336 \\
(0.317)\end{array}$ & $\begin{array}{c}0.215 \\
(0.235)\end{array}$ \\
\hline \multirow[t]{2}{*}{ R-Squared } & - & 0.634 & - & 0.059 & 0.085 & 0.082 & 0.131 & 0.115 \\
\hline & \multicolumn{2}{|c|}{$2-2$} & \multicolumn{6}{|c|}{$(2-2)-(4-4)$} \\
\hline$\alpha_{2-2}^{P d 2}(\%)$ & $\begin{array}{c}0.092 \\
(0.334)\end{array}$ & $\begin{array}{c}0.033 \\
(0.160)\end{array}$ & $\begin{array}{l}-0.035 \\
(0.180)\end{array}$ & $\begin{array}{l}-0.062 \\
(0.186)\end{array}$ & $\begin{array}{l}-0.098 \\
(0.166)\end{array}$ & $\begin{array}{l}-0.080 \\
(0.199)\end{array}$ & $\begin{array}{l}-0.041 \\
(0.237)\end{array}$ & $\begin{array}{l}-0.054 \\
(0.150)\end{array}$ \\
\hline R-Squared & - & 0.748 & - & 0.038 & 0.062 & 0.040 & 0.166 & 0.201 \\
\hline \multicolumn{9}{|c|}{ Test of equal $\alpha, \mathrm{p}$-value } \\
\hline$\alpha_{0-4}^{P d 2}=\alpha_{2-4}^{P d 2}$ & 0.765 & 0.801 & 0.703 & 0.708 & 0.841 & 0.738 & 0.404 & 0.619 \\
\hline$\alpha_{0-4}^{P d 2}=\alpha_{0-0}^{P d 2}$ & 0.117 & 0.281 & 0.213 & 0.214 & 0.339 & 0.432 & 0.154 & 0.395 \\
\hline$\alpha_{0-4}^{P d 2}=\alpha_{2-2}^{P d 2}$ & 0.532 & 0.803 & 0.751 & 0.668 & 0.680 & 0.787 & 0.797 & 0.697 \\
\hline Factor Model & None & $4 \mathrm{~F}$ & None & CAPM & $4 \mathrm{~F}$ & $4 \mathrm{~F}$ & $4 \mathrm{~F}$ & $4 \mathrm{~F}$ \\
\hline Buy and Hold & No & No & No & No & No & Yes & Yes & No \\
\hline Value Weighted & No & No & No & No & No & No & Yes & No \\
\hline Industry Matched & No & No & No & No & No & No & No & Yes \\
\hline
\end{tabular}

Note: The entries in columns 1 and 2 are the parameter estimates and heteroscedasticity-consistent standard errors (in parentheses) on the constant from the estimation of versions of equation (2). Columns 3-8 are based on estimates of equation (3). Bold-face panel headings denote groups and the specification details are at the bottom of the table. The sample size is 58 weeks. "CAPM" indicates that the regression controls for the return on the market. " $4 \mathrm{~F}$ " indicates controls for the market, size, book-to-market, and momentum factors. Details on these factors, as well as our methodology for "buy and hold" returns, value weighting, and adjusting for industry returns are provided in the text. 


\section{TABLE VII}

Change in Operating Performance, 1962-1966

\begin{tabular}{|c|c|c|c|c|}
\hline \multirow{3}{*}{$\begin{array}{l}\text { Dependent Variable } \\
\text { Sample }\end{array}$} & (1) & $(2)$ & $(3)$ & $(4)$ \\
\hline & \multicolumn{2}{|c|}{ Net Income Growth } & \multicolumn{2}{|c|}{ Sales Growth } \\
\hline & Survivors & Assigned & Survivors & Assigned \\
\hline \multirow[t]{2}{*}{ 0-4 Indicator } & 0.038 & 0.030 & 1.091 & 0.835 \\
\hline & $(0.015)$ & $(0.012)$ & $(0.149)$ & $(0.121)$ \\
\hline \multirow[t]{2}{*}{ 2-4 Indicator } & 0.013 & 0.012 & 0.171 & 0.161 \\
\hline & $(0.009)$ & $(0.008)$ & $(0.091)$ & $(0.077)$ \\
\hline \multirow[t]{2}{*}{$\ln ($ Assets 1962) } & -0.002 & -0.001 & -0.104 & -0.089 \\
\hline & $(0.003)$ & $(0.002)$ & $(0.025)$ & $(0.022)$ \\
\hline$R^{2}$ & 0.020 & 0.019 & 0.063 & 0.049 \\
\hline $\mathrm{N}$ & 2,408 & 2,799 & 2,331 & 2,741 \\
\hline
\end{tabular}

Notes: "Net Income Growth" is defined as (Net Income in 1966 - Net Income in 1962)/Market Capitalization in 1962. "Sales Growth" is defined as (Sales in 1966 - Sales in 1962)/Sales in 1962. Sample is based on 0-4, 2-4, and 4-4 firms as of January 1963. The excluded category is 4-4 firms. In columns 1 and 3, the sample is restricted to those firms for which comparable 1966 information was available. In columns 2 and 4, firms with missing growth information were assigned the 10th or 50th percentile of firms in its group (see text for further details). The top and bottom one percent of observations in terms of the dependent variable are dropped. Regressions include 1-digit SIC dummies. The sample means of the dependent variable in columns $1-4$ are $0.093,0.091,0.863$, and 0.857 , respectively. 


\section{APPENDIX 1:}

\section{Treatment Of Firm Changes For OTC Firms}

\begin{tabular}{lccccc}
\hline \hline & Jan 63 & Jan 64 & Jan 65 & Jan 66 & Dec 66 \\
\hline Sample size & 1196 & 1129 & 1053 & 986 & 941 \\
(a) Move to NYSE/AMEX & 87 & 83 & 65 & 39 & 39 \\
Continued & 87 & 83 & 65 & 7 \\
(b) Name change & 9 & 15 & 10 & 6 \\
Continued & 6 & 10 & 6 & $1(0 / 1)$ \\
Not continued (ER assigned/not assigned) & $3(1 / 2)$ & $5(3 / 2)$ & $4(3 / 1)$ & 25 \\
(c) Merger & 30 & 38 & 36 & $18(16 / 2)$ \\
Continued (merger week return ass./not ass.) & $23(20 / 3)$ & $28(20 / 8)$ & $24(19 / 5)$ & $7(6 / 1)$ \\
Not continued (merger week return ass./not ass.) & $7(4 / 3)$ & $10(8 / 2)$ & $12(9 / 3)$ & 5 \\
(d) Liquidations & 5 & 5 & 5 & $5(3 / 2)$ \\
Not continued (ER assigned/not assigned) & $5(3 / 2)$ & $5(1 / 4)$ & $5(3 / 2)$ & 13 \\
(e) Exit from Barron's, last price $>\$ 2$ & 29 & 14 & 14 & $13(12 / 1)$ \\
Not continued (ER assigned/not assigned) & $29(28 / 1)$ & $14(13 / 1)$ & $14(10 / 4)$ & 17 \\
(f) Exit from Barron's, last price $\leq \$ 2$ & 39 & 22 & 16 & $17(11 / 6)$ \\
Not continued (ER assigned/not assigned) & $39(31 / 8)$ & $22(19 / 3)$ & $16(13 / 3)$ & 106 \\
\hline Total exits/changes & 198 & 177 & 138 & 95 \\
\hline Total series continued & 116 & 121 & 95 & \\
\hline \hline
\end{tabular}

Note: "ER" stands for "exit return". Among the firms with discontinued time series of returns, "ER assigned" / "not assigned" refers to firms for which it was possible/impossible to assign exit returns within 20 weeks of the last Barron's price. Overall, we succeeded in assigning an exit return for 78 percent of the 233 firms where the time series of returns was not continued. The number of observations at the beginning of the following year does not exactly equal the number of observations at the beginning of the current year, minus the number of exits/changes, plus the number of series that are continued. This is because an exit return may only be assigned in the following calendar year. Furthermore, series that are continued may again be subject to one of the changes in (a)-(f). Such changes are not included in the above counts. 


\section{APPENDIX II:}

Factor Loadings by Group and Period

\begin{tabular}{|c|c|c|c|c|c|c|c|c|}
\hline & $\operatorname{Pd} 1$ & $\operatorname{Pd} 2$ & $\operatorname{Pd} 1$ & $\operatorname{Pd} 2$ & $\operatorname{Pd} 1$ & $\operatorname{Pd} 2$ & $\operatorname{Pd} 1$ & $\operatorname{Pd} 2$ \\
\hline & \multicolumn{8}{|c|}{ OTC Groups } \\
\hline & \multicolumn{2}{|c|}{$0-4$} & \multicolumn{2}{|c|}{$2-4$} & \multicolumn{2}{|c|}{$0-0$} & \multicolumn{2}{|c|}{$2-2$} \\
\hline \multirow[t]{2}{*}{ Market Factor Beta } & 0.701 & 0.866 & 0.750 & 0.837 & 0.588 & 0.815 & 0.720 & 0.783 \\
\hline & $(0.056)$ & $(0.061)$ & $(0.057)$ & $(0.057)$ & $(0.106)$ & $(0.147)$ & $(0.131)$ & $(0.109)$ \\
\hline \multirow[t]{2}{*}{ Size Factor Beta } & 0.651 & 0.904 & 0.725 & 0.892 & 0.868 & 1.209 & 0.977 & 1.294 \\
\hline & $(0.117)$ & $(0.133)$ & $(0.117)$ & $(0.095)$ & $(0.186)$ & $(0.259)$ & $(0.204)$ & $(0.193)$ \\
\hline \multirow[t]{2}{*}{ Book/Market Factor Beta } & 0.014 & 0.236 & 0.070 & 0.282 & 0.037 & 0.345 & 0.205 & 0.565 \\
\hline & $(0.085)$ & $(0.059)$ & $(0.081)$ & $(0.700)$ & $(0.146)$ & $(0.282)$ & $(0.177)$ & $(0.321)$ \\
\hline \multirow[t]{2}{*}{ Momentum Factor Beta } & 0.054 & -0.248 & -0.011 & -0.170 & 0.159 & -0.187 & -0.200 & -0.028 \\
\hline & $(0.074)$ & $(0.084)$ & $(0.085)$ & $(0.060)$ & $(0.139)$ & $(0.198)$ & $(0.175)$ & $(0.170)$ \\
\hline \multirow[t]{3}{*}{$\mathrm{R}^{2}$} & 0.639 & 0.912 & 0.667 & 0.938 & 0.326 & 0.634 & 0.296 & 0.748 \\
\hline & \multicolumn{8}{|c|}{ NYSE/AMEX Comparison Groups } \\
\hline & \multicolumn{2}{|c|}{ For $0-4$} & \multicolumn{2}{|c|}{ For $2-4$} & \multicolumn{2}{|c|}{ For $0-0$ and $2-2$} & & \\
\hline \multirow[t]{2}{*}{ Market Factor Beta } & 0.840 & 0.982 & 0.868 & 0.992 & 0.747 & 0.944 & & \\
\hline & $(0.039)$ & $(0.038)$ & $(0.037)$ & $(0.038)$ & $(0.070)$ & $(0.062)$ & & \\
\hline \multirow[t]{2}{*}{ Size Factor Beta } & 0.969 & 1.087 & 0.985 & 1.089 & 1.039 & 1.357 & & \\
\hline & $(0.062)$ & $(0.079)$ & $(0.061)$ & $(0.082)$ & $(0.107)$ & $(0.141)$ & & \\
\hline \multirow[t]{2}{*}{ Book/Market Factor Beta } & 0.250 & 0.268 & 0.214 & 0.245 & 0.245 & 0.341 & & \\
\hline & $(0.062)$ & $(0.060)$ & $(0.063)$ & $(0.058)$ & $(0.104)$ & $(0.095)$ & & \\
\hline \multirow[t]{2}{*}{ Momentum Factor Beta } & -0.104 & -0.067 & -0.115 & -0.063 & -0.208 & -0.123 & & \\
\hline & $(0.070)$ & $(0.053)$ & $(0.068)$ & $(0.052)$ & $(0.126)$ & $(0.098)$ & & \\
\hline $\mathrm{R}^{2}$ & 0.875 & 0.974 & 0.886 & 0.974 & 0.680 & 0.925 & & \\
\hline
\end{tabular}

Note: The entries are the factor loadings (betas) on the four factors in the estimation of equation (2). Heteroscedastic-consistent standard errors are in parentheses. 


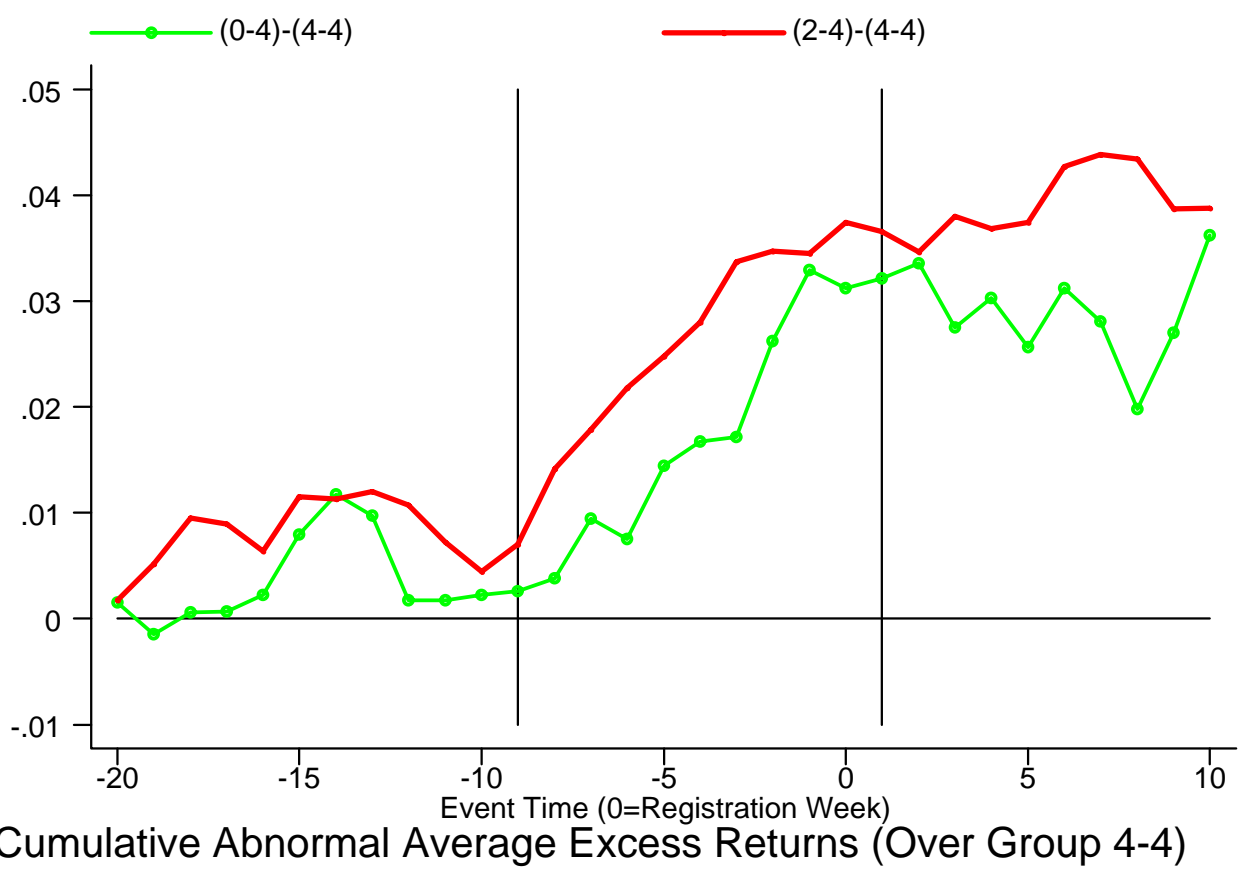

Figure I. Cumulative Abnormal Excess Returns Near SEC Registration 


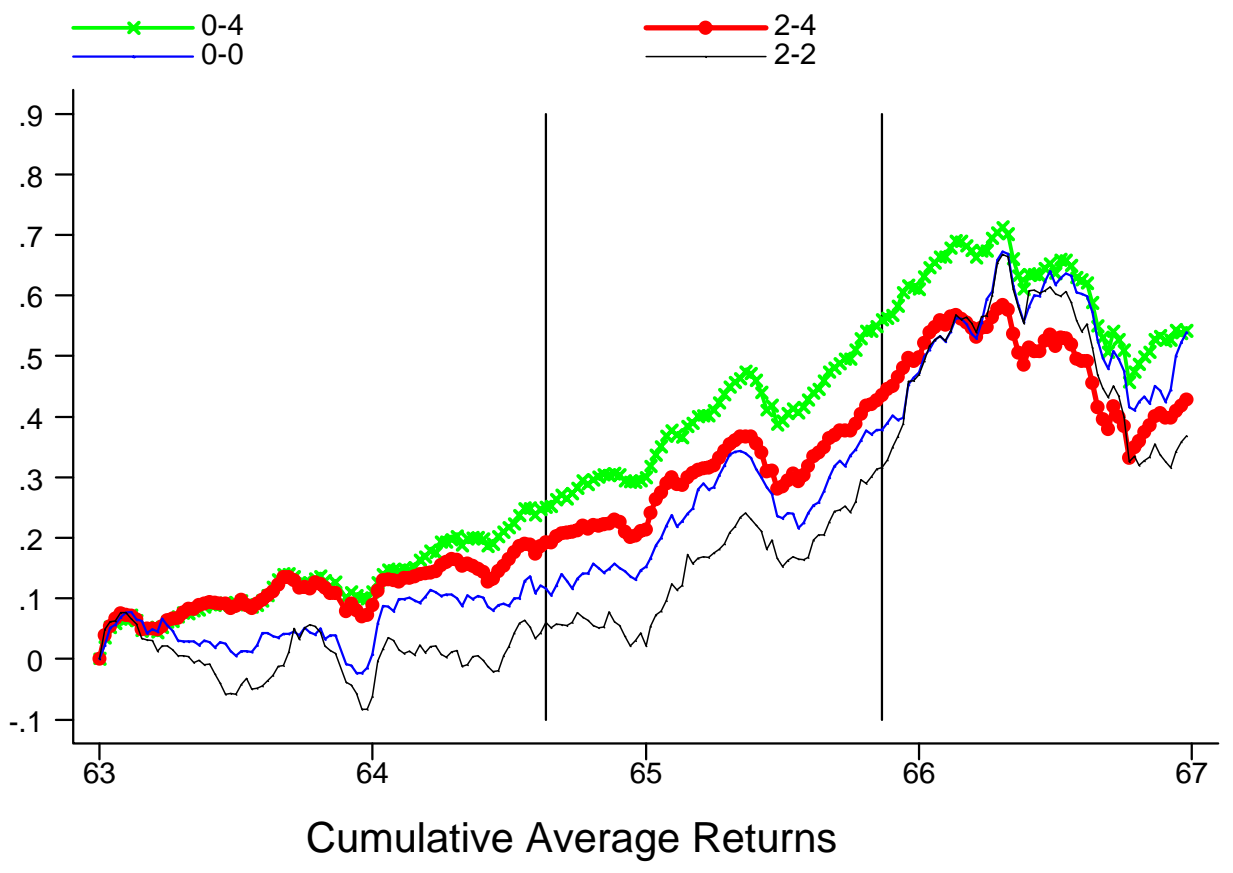

Figure IIa. Cumulative Returns By Group, OTC firms, 1963-1966

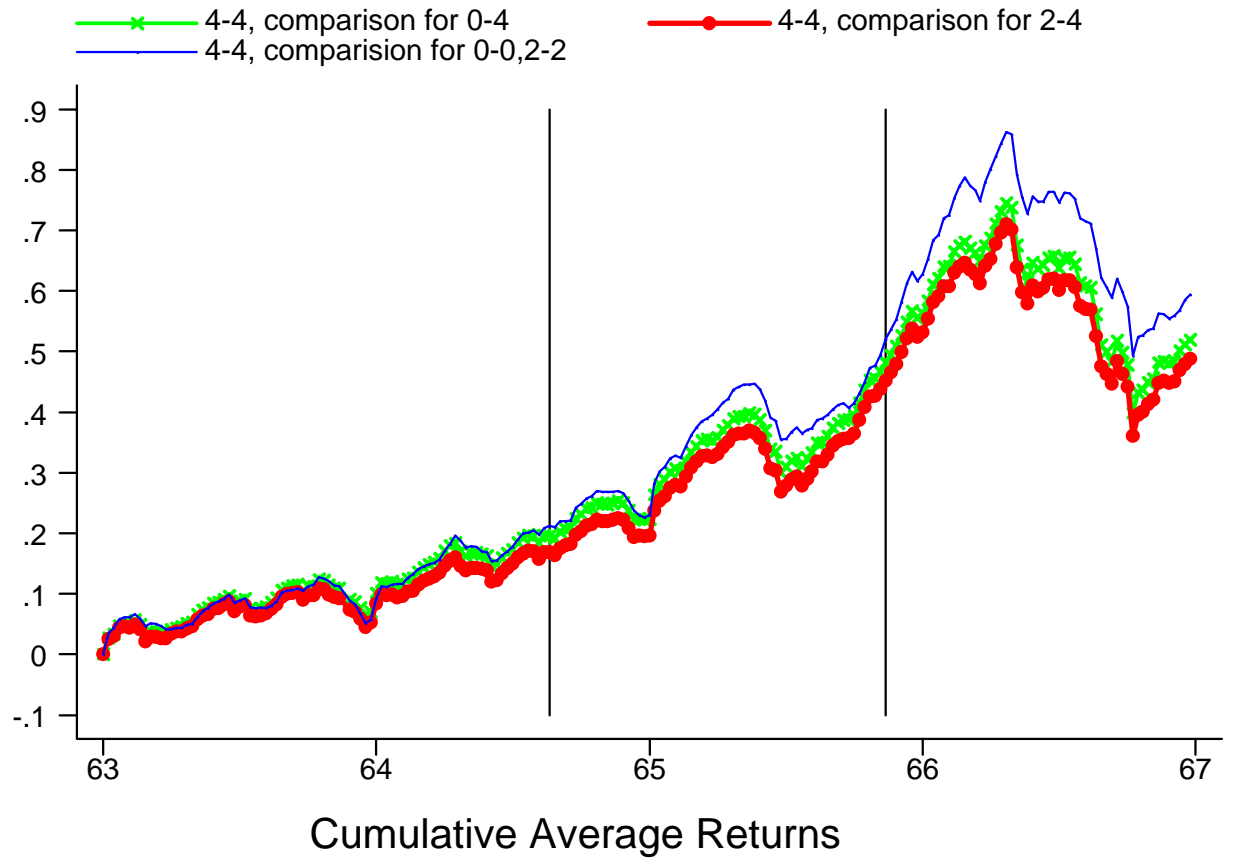

Figure IIb. Cumulative Returns By Group, NYSE/AMEX Comparison Groups, 1963-1966 


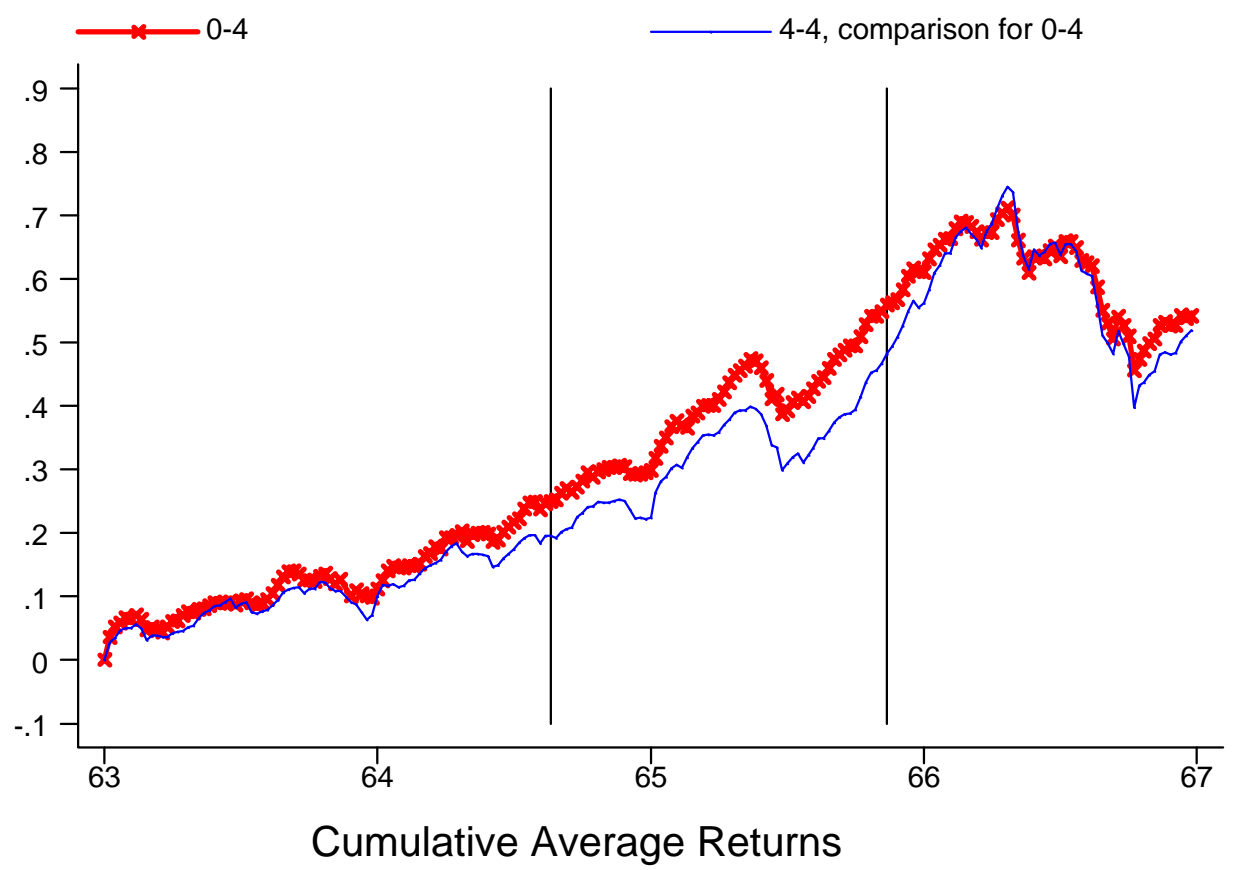

Figure IIIa. Cumulative Returns Of OTC Group 0-4 And Its NYSE/AMEX Comparison Group, 1963-1966

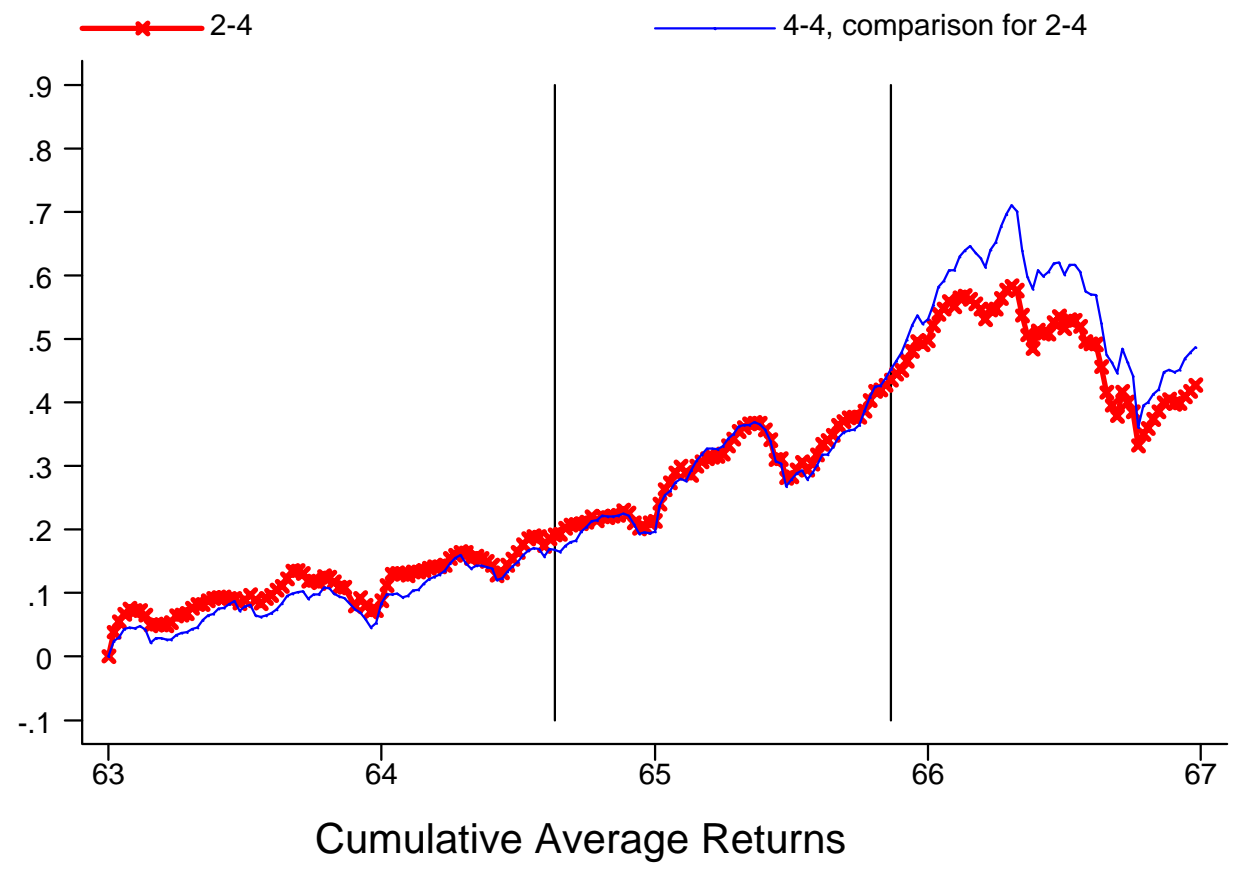

Figure IIIb. Cumulative Returns Of OTC Group 2-4 And Its NYSE/AMEX Comparison Group, 1963-1966

Note: Vertical lines in Figures 2a, 2b, 3a, and 3b are at the ends of Period 1a and Period 1b. See text for further details. 